OPEN ACCESS

Edited by:

Shuang Wang,

Zhejiang University, China

Reviewed by:

Shuli Liang,

Capital Medical University, China

Olagide Wagner Castro,

Federal University of Alagoas, Brazil

${ }^{*}$ Correspondence:

Thomas N. Ferraro

ferrarot@rowan.edu

tThese authors have contributed equally to this work

Specialty section:

This article was submitted to

Epilepsy,

a section of the journal

Frontiers in Neurology

Received: 16 January 2020

Accepted: 12 May 2020

Published: 23 June 2020

Citation:

Re CJ, Batterman Al, Gerstner JR, Buono RJ and Ferraro TN (2020) The Molecular Genetic Interaction

Between Circadian Rhythms and

Susceptibility to Seizures and

Epilepsy. Front. Neurol. 11:520.

doi: 10.3389/fneur.2020.00520

\section{The Molecular Genetic Interaction Between Circadian Rhythms and Susceptibility to Seizures and Epilepsy}

\author{
Christopher J. Re ${ }^{1 \dagger}$, Alexander I. Batterman ${ }^{1 \dagger}$, Jason R. Gerstner ${ }^{2}$, Russell J. Buono ${ }^{1}$ and \\ Thomas N. Ferraro ${ }^{1 *}$ \\ ${ }^{1}$ Department of Biomedical Sciences, Cooper Medical School of Rowan University, Camden, NJ, United States, ${ }^{2}$ Department \\ of Biomedical Sciences, Elson S. Floyd College of Medicine, Washington State University, Spokane, WA, United States
}

Seizure patterns observed in patients with epilepsy suggest that circadian rhythms and sleep/wake mechanisms play some role in the disease. This review addresses key topics in the relationship between circadian rhythms and seizures in epilepsy. We present basic information on circadian biology, but focus on research studying the influence of both the time of day and the sleep/wake cycle as independent but related factors on the expression of seizures in epilepsy. We review studies investigating how seizures and epilepsy disrupt expression of core clock genes, and how disruption of clock mechanisms impacts seizures and the development of epilepsy. We focus on the overlap between mechanisms of circadian-associated changes in SCN neuronal excitability and mechanisms of epileptogenesis as a means of identifying key pathways and molecules that could represent new targets or strategies for epilepsy therapy. Finally, we review the concept of chronotherapy and provide a perspective regarding its application to patients with epilepsy based on their individual characteristics (i.e., being a "morning person" or a "night owl"). We conclude that better understanding of the relationship between circadian rhythms, neuronal excitability, and seizures will allow both the identification of new therapeutic targets for treating epilepsy as well as more effective treatment regimens using currently available pharmacological and non-pharmacological strategies.

\footnotetext{
Keywords: clock gene, neuronal excitability, voltage-gated sodium (Nav) channels, inward rectifying K channels, chronotherapy
}

\section{INTRODUCTION}

Across evolution, nearly all eukaryotic organisms, including humans, have relied on predictable cycles of sustained activity and rest for survival. Cycles of activity and rest occur in essentially all cells of the body (peripheral oscillations), but they are largely governed by a primary oscillating mechanism (sometimes referred to as a "master clock") that occurs in neurons of the suprachiasmatic nucleus (SCN) of the hypothalamus $(1,2)$. In addition to influencing the sleep/wake cycle, protein products of the primary oscillating mechanism have broad impact on homeostatic processes at the cellular (e.g., cell cycle regulation, energy metabolism) and systems (e.g., endocrine, immune, cardiovascular, pulmonary, gastrointestinal, and nervous) levels. 
In the present paper, we review circadian influences relevant to nervous system dysfunction associated with epilepsy. We describe clinical studies and studies using experimental animals showing that alteration of genes mediating function of the mammalian biological clock can influence the expression of seizures, and conversely that seizures can alter the expression of clock genes and activity in related gene pathways. We then discuss the clinical significance of the relationship between the time of day and excitability of the nervous system leading to a seizure, highlighting studies that report patterns into which seizures cluster in several types of epilepsy.

An overarching postulate guiding this review is that circadian factors underlie mechanisms that lead to abnormal neuronal excitability in specific "epileptogenic" areas of the brain, resulting in seizures and epilepsy. At the same time, there is also focus on the idea that individual seizures disrupt both biological clock mechanisms and brain function related to circadian or diurnal rhythms. This may lead to biomolecular changes required to initiate the process of epileptogenesis, and establish chronic epilepsy. The goal of this work is to provide better understanding of the interrelationship between circadian rhythms, clock genes, and neuronal excitability, thereby providing deeper insight into the nature of seizure activity, and aiding initiatives to develop new strategies for the treatment of epilepsy.

\section{TIME OF DAY AND SLEEP/WAKE EFFECTS ON SEIZURES IN EPILEPSY}

A seizure is defined broadly as a period of abnormal, synchronous excitation of a populous of neurons and neural pathways resulting from an imbalance of GABAergic and glutamatergic neurotransmission (3). Seizures may occur due to reversible insults such as infection, fever, trauma, hypoglycemia, stroke or tumor. They may be triggered by sleep deprivation or by withdrawal from drugs of abuse. In contrast, epilepsy is a chronic condition of unprovoked recurrent seizures, arising from a persistent dysfunction in neuronal excitability (4). When it develops as a result of an irreversible insult, it is known as acquired epilepsy. Epilepsy that develops in the absence of any known cause is generally considered to have a strong genetic component and is referred to as idiopathic. An epilepsy syndrome describes patients who can be grouped by their phenotypic similarities with respect to electroencephalography (EEG) findings, age of onset, response to medications and other clinical characteristics. The formal definition of epilepsy was recently updated by a Task Force of the International League Against Epilepsy (5).

For some people with epilepsy, seizures occur in a predictable pattern or cycle over the course of a month, week, or day (6). Seizures may be clearly associated with sleep/wake states. For other patients, seizures appear to be random events. Clinical studies making use of seizure tracking databases as well as those examining patients undergoing video-EEG monitoring have revealed significant trends between time of day and/or circadian phase and peak occurrence of seizures in specific types of epilepsy. Thus, analysis of records from the SeizureTracker database between the years of 2007 and 2015 (1,118 patients included) revealed that $14-22 \%$ of patients demonstrated seizure cycles $>3$ weeks, 7-21\% showed strong weekly cycles, and over $80 \%$ exhibited a phenotype in which seizure rate was influenced either by the time of day (i.e., by the hour), circadian rhythms, or sleep/wake state (7). These data suggest that the majority of people with epilepsy exhibit seizures with some degree of periodicity.

Different seizure phenotypes have been shown to occur more frequently at different times of the day (we define daytime as 6:00-18:00 and nighttime as 19:00-5:00) and sleep/wake state. Focal seizures of temporal lobe origin have been documented to occur mainly during wakefulness and to peak in the afternoon and early morning (8-14). Seizures originating from the occipital lobe have also been linked to wakefulness and daytime $(8,9)$. In addition, wakefulness and daytime have been associated with generalized, atonic, myoclonic, and hypomotor seizures $(15,16)$. Wakefulness specifically has been tied to auras and epileptic spasms, as well as absence, gelastic and dialeptic seizures $(9,16$, 17). Conversely, there are seizure phenotypes that typically occur during the night and while sleeping. These include automotor, hypermotor, tonic, and clonic seizures $(9,16,17)$, along with focal seizures originating from the frontal $(8-11)$ and parietal lobes $(8,16)$. Juvenile myoclonic epilepsy (JME), a common form of generalized epilepsy, is characterized by EEG and clinical seizures that are associated closely with the sleep/wake cycle, especially transition phases such as falling asleep and awakening (18).

In a few studies, the time at which certain seizure types peaked was influenced by patient age. For instance, in one report, focal seizures originating from the frontal lobe occurred typically at night in adolescents but during the day in infants, with a trend for increased seizure probability at night as age increased (15). An additional variable that warrants consideration is seizure severity, which appears to be highest during the day (19). In particular, status epilepticus has been reported to occur most frequently later in the day in infants and in the morning in older children $(20,21)$. For both infants and older children, status epilepticus occurrences appear to diminish at night.

Whereas seizures occur more often during wakefulness in patients with generalized epilepsy, interictal epileptiform discharges occur with greater frequency during sleep, predominantly non-rapid eye movement (NREM) sleep, with the highest rate of epileptiform discharges observed in the hour following onset of sleep and in the hour prior to the onset of wakefulness (22). Brief epileptiform electrical disturbances are not known to be directly correlated with behavioral seizures; however, individuals who exhibit abnormal EEG discharges are more likely to develop epilepsy (23) and drug treatment of interictal EEG abnormalities reduces epilepsy-associated comorbidities (24). Thus, it is possible that epileptiform discharges may represent a type of kindling phenomenon such that accumulation of electrical disturbances during sleep leads to the expression of seizures during wakefulness. Further research is required to fully elucidate the relationship between epileptiform discharges during sleep and behavioral seizures during wakefulness. 
Interaction between sleep and seizures in certain forms of epilepsy occurs independent of the time of day, suggesting that there are fundamental mechanisms of sleep that increase the electrical excitability of neurons participating in seizure initiation. Sleep spindles are an electrographic signature of sleep that correlate in frequency with interictal spike-wave discharges (25) and may be biomarkers of epilepsy in humans (26). They are relevant in both generalized (27) as well as focal epilepsy (28) and display altered morphology in many epilepsy patients (29). Sleep spindles are also subject to regulation by circadian rhythms (30). They may occur independently or may occur in association with epileptiform discharges (31). In addition to serving as biomarkers of epilepsy, sleep spindles may also have functional significance (32), such as in absence epilepsy where they may evolve into spike wave discharges (33). The reticular nucleus of the thalamus controls both sleep spindles and epileptiform discharges (34), an anatomical correlation that is consistent with a functional role for sleep spindle mechanisms in seizures and epilepsy. Although animal models provide support for an association between sleep spindles and epilepsy (35), recent evidence indicates that spike-wave discharges are not pathological sleep spindles (36). Additional research is required to clarify possible mechanistic links between changes in sleep spindle characteristics and epileptogenesis.

Other sleep-related phenomena to consider in relation to epilepsy include neocortical slow oscillations, which are seen in cortical and thalamic neurons when consciousness is suppressed, including during coma and natural sleep (37). At the cellular level, these oscillations are characterized by depolarized "Up" states and hyperpolarized "Down" states, with neurons in the Up state having increased firing rate and decreased input resistance. A few studies suggest that these states are also present in epileptic seizures that occur both in humans (38) and rodents (39), which is interesting, given that many seizure types also inhibit consciousness. One study using in vivo whole-cell recordings in a rat model of focal limbic seizures found that the membrane potential of frontal cortical secondary motor cortex layer 5 neurons oscillated during seizures and produced Up and Down states comparable to those seen during anesthesia (39). Taken together, these findings shed light on mechanisms potentially linking sleep with certain types of seizures in epilepsy.

Within the context of sleep influences on epilepsy, syndromes of sleep-related hypermotor epilepsy are noteworthy (40). These syndromes include what previously were known as nocturnal epilepsies; however, a change in name was recommended to emphasize that these epilepsies are associated with sleep rather than the time of day. Sleep-related seizures involve characteristic and complex motor features that are often unique to individual patients (40). They generally arise from frontal cortex although they may also originate from other cortical areas. Compared to patients with seizure foci in the frontal cortex, sleeprelated hypermotor seizure patients with foci in other cortical areas exhibit seizures with a longer duration and a shorter electrographic to behavioral latency (41).

There is a strong association between focal cortical dysplasia (FCD) and medication refractory sleep-related hypermotor epilepsy (42). FCD is classified into several types based on severity and cortical pathology, and is caused in part by somatic cell mutations that lead to abnormal development of the cerebral cortex (42). Mutations in genes involved in the mammalian target of rapamycin (mTOR) signaling cascade and the GATOR complex that negatively regulates mTOR signals have been implicated in FCD with sleep-related hypermotor epilepsy, including DEPDC5, NPRL2, and NPRL3 (43).

Pharmacotherapy of sleep-related epilepsies is syndrome dependent (44). Progress in understanding the genetic contributions to sleep-related epilepsies (45), especially the role of mutations in genes that encode subunits of acetylcholine receptors (46), has led to more rational treatment strategies including nicotine patches and other drugs that modify cholinergic neurotransmission; however, like common forms of epilepsy, up to one-third of patients are refractory to available medications $(47,48)$. Despite advances in making diagnoses for the sleep-related epilepsies based on genetic testing, causative mutations are documented in only about $30 \%$ of cases (45). Figure 1 [based on (55)] summarizes the types of epilepsy in which seizures cluster in daily patterns, relating sleep/wake states with major factors that promote changes in circadian phase.

\section{Terminology and Definitions Zeitgebers}

Environmental stimuli (e.g., blue light or temperature) that are cues to entrain the circadian rhythm of an organism.

\section{Diurnal Rhythm}

The oscillation of a phenotype (e.g., feeding behavior or gene expression) over the course of a day in the presence of a zeitgeber.

\section{Circadian Rhythm}

A daily (roughly $24 \mathrm{~h}$ ) behavioral or physiological process of an organism that is regulated by an endogenous, entrainable oscillator, which is maintained in the absence of zeitgebers.

\section{Suprachiasmatic Nucleus (SCN)}

A brain region within the hypothalamus, and dorsal to (i.e., above) the optic chiasm, that is responsible for controlling circadian rhythms.

\section{Zeitgeber Times (ZTs)}

ZTs relate to the current position of an organism within the light/dark cycle (56). In the context of preclinical research, laboratory animals are typically subjected to $12 \mathrm{~h}$ of light and $12 \mathrm{~h}$ of darkness. In this example, ZT0 represents light onset, whereas ZT12 represents darkness onset (i.e., lights off).

\section{Circadian Times (CTs)}

A standard unit of time based on the endogenous free-running period of a rhythm. For example, CT can relate to the current phase within the entire span of the circadian period that is being experienced by the organism in the absence of a zeitgeber.

\section{Diurnal vs. Nocturnal}

These two terms typically relate to the phase in the light/dark cycle in which the species or individual in question is active. Diurnal organisms such as humans are active and exhibit 


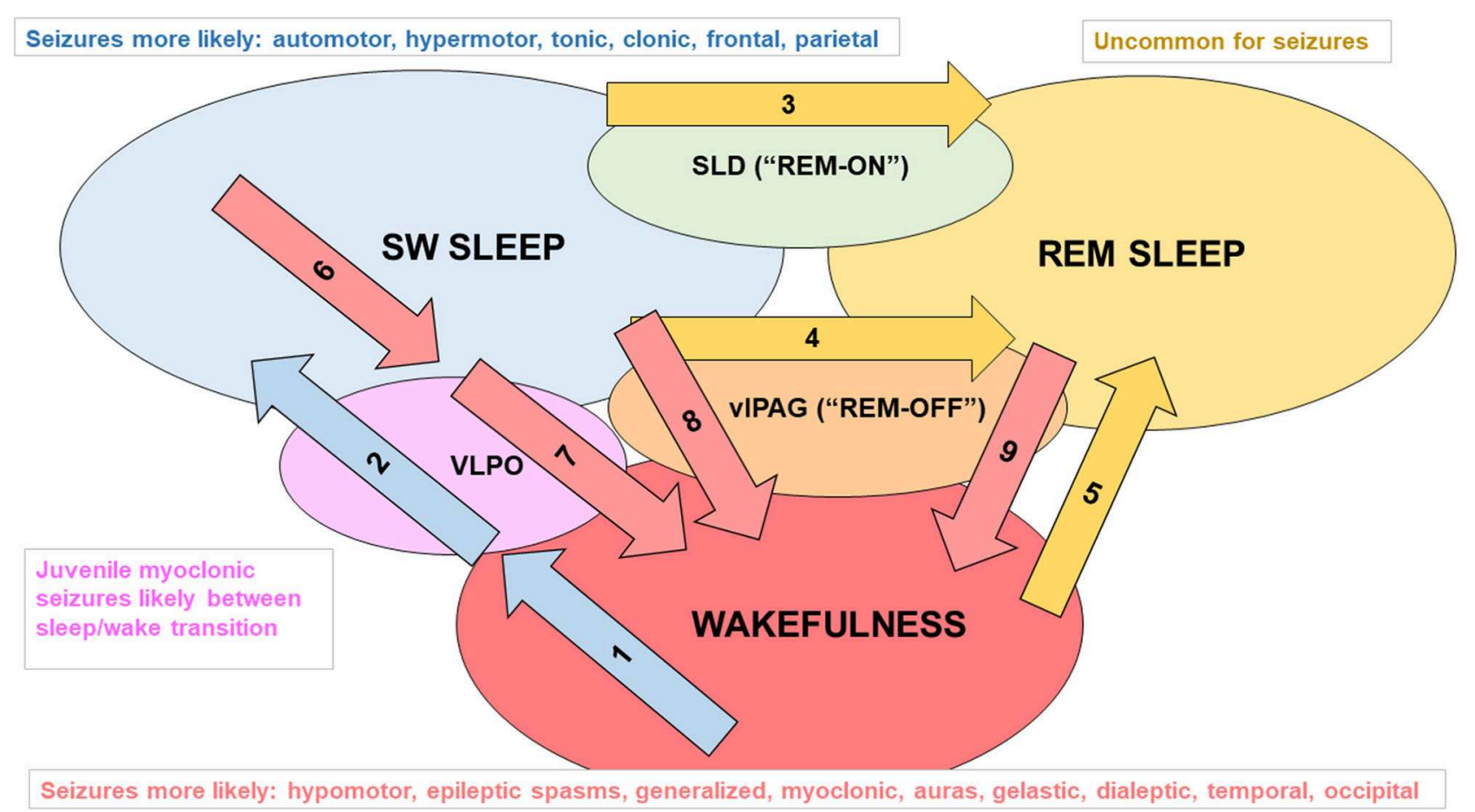

FIGURE 1 | Examples of factors that promote changes in sleep/wake state and seizure types associated with each sleep/wake state. Mammals have two main cycles: the $24 \mathrm{~h}$ sleep/wake cycle and multiple $90 \mathrm{~min}$ slow wave sleep (SWS, i.e., NREM)/REM sleep cycles that typically occur within a 6 to $8 \mathrm{~h}$ period of sleep/inactivity. The sleep/wake state of an individual is influenced by various levels of endogenous clock products (that oscillate in a circadian rhythm) as well as external stimuli (zeitgebers) and allostatic factors (relate to the regulation and maintenance of sleep homeostasis) that act on the suprachiasmatic nucleus (SCN). Daylight is an example of a zeitgeber. It acts on melanopsin-containing retinal ganglion cells that transmit signals indicating the levels of environmental light (and thus the likely time of day) through the retinohypothalamic pathway to neurons of the SCN (49). Diminishing daylight reduces the inhibitory signaling of SCN projections to the pineal gland, enabling melatonin secretion. The SCN also regulates sustained sleep/wake states, as lesions of the SCN in rodents disrupt circadian rhythms and lead to random short bursts of sleep and wakefulness (50). Influences on flux in the direction of SWS: Arrow 1: adenosine accumulating from daytime glycogen use, increased release of melatonin in the evening and beyond; Arrow 2: adenosine activating ventrolateral preoptic area (VLPO) "Sleep" neurons (foot on SWS gas pedal) (51-53), decreased activity of orexinergic neurons, and allostatic factors (e.g., leptin release after large dinner) promoting VLPO firing. Influences on flux in the direction of REM sleep: Arrow 3: glutamate activating the "REM-ON" neurons of the sublaterodorsal nucleus (SLD, foot on REM gas pedal) (54); Arrow 4: decreased excitatory input to REM-OFF neurons of the ventrolateral periaqueductal gray matter (VIPAG, foot off REM brakes); Arrow 5: orexinergic dysfunction (e.g., narcolepsy). Influences on flux in the direction of wakefulness: Arrow 6: adenosine levels diminishing from glycogen regeneration, decreasing melatonin secretion; Arrow 7: VLPO receiving inhibitory input from "wakefulness neurons" including orexinergic neurons in the lateral hypothalamus, noradrenergic (NE) neurons in the locus coeruleus, serotonergic $(5 \mathrm{HT})$ neurons in the raphe nuclei, histaminergic neurons of the tuberomammillary nucleus, and cholinergic neurons of the pons, basal forebrain, and medial septum (foot off wake brake), and a lack of excitatory adenosine (foot off SWS gas pedal); arrow 8: diminished firing of NE and 5HT at vIPAG (foot off wake brake); arrow 9: REM-OFF activated by orexinergic, $5 \mathrm{HT}$, and NE neuronal firing (foot on wake gas).

catabolic activity mostly during the light phase, whereas nocturnal organisms such as mice and rats are active and exhibit catabolic activity mostly during the dark phase. Consequently, diurnal and nocturnal organisms are in an inactive/anabolic state during the dark and light phases, respectively.

More information on terminology is found in Karatsoreos and Silver (56), Karatsoreos Eban-Rothschild and Bloch (57), and Voigt et al. (58).

\section{CORE CLOCK MECHANISMS INFLUENCE NEURONAL EXCITABILITY}

Time of day-dependent gene expression pathways generate circadian rhythms in most all somatic cells in the body, taking cues from the SCN and hypothalamus driven by zeitgebers (See Terminology Section). Critical protein products of this primary oscillating mechanism are encoded by period (Per1, Per2, Per3) and cryptochrome (Cry1, Cry2) genes (49). Figure 2 [adapted from (59)], provides a more comprehensive summary of core circadian clock genes and also draws connections between critical clock feedback loops and epilepsy. Overall, two main feedback loops lead to the cyclical fluctuation of levels of "clock proteins" that go on to activate/inactivate other biomolecular processes/substrates (e.g., "clock-controlled genes") in a time-dependent manner, i.e., circadian regulation (60). These oscillations occur in both primary time-keeping cells (i.e., those of the SCN) and peripheral cells (i.e., essentially all other cells, both nervous and otherwise), though the circadian phase may be shifted from tissue to tissue within an organism, 


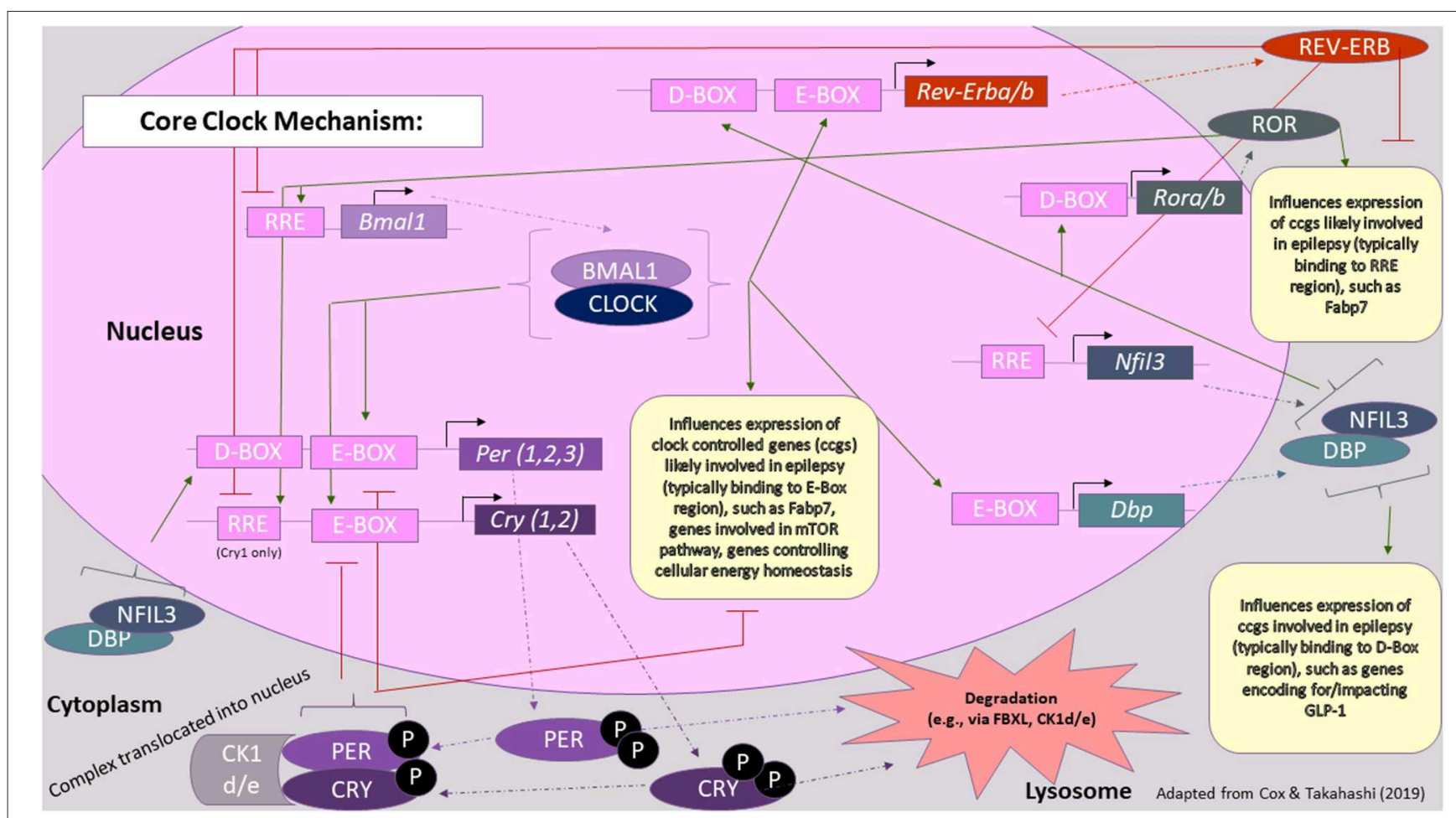

FIGURE 2 | Core clock mechanism in the context of epilepsy. The core clock mechanism consists of three main feedback loops, which are thought to involve PER/CRY, REV-ERB/ROR, and DBP/NFIL3, respectively. Key proteins involved in these loops, whose levels fluctuate over the course of the day, are thought to also influence the expression of genes involved in seizure susceptibility or epileptic processes. Green arrows represent transcriptional activation, whereas red lines represent transcriptional repression. Rectangles represent genes and other DNA sequences of note, whereas ovals represent proteins. For a more comprehensive review on the processes underlying the molecular clock, please refer to (59) [Figure modified from (59)].

depending on how the tissue is connected to or responds to signals originating from the SCN, including photic and nonphotic cues (i.e., feeding schedules).

Insight into the relationship between circadian rhythms and seizures comes first from studies showing that the time of day regulates neuronal excitability (61). Circadian-associated changes in intrinsic membrane properties of SCN neurons modulates inputs from other brain areas including thalamus and retina, especially at synapses utilizing GABA, a neurotransmitter whose altered function has been long-associated with epilepsy (62-65). GABA receptor activity governing excitability of SCN neurons changes in a circadian fashion via degradation mediated by a signaling mechanism involving the clock-related gene Fbxl4 (66). Interestingly, mutations in FBXL4 cause a mitochondrial disease characterized by a clinical syndrome that includes epilepsy (67).

Diverse ion channel proteins expressed uniquely in various subtypes of neurons determine the electrophysiological properties of neuronal membranes. In primary time-keeping neurons, cellular redox conditions govern circadian-dependent fluctuations in ion channel function and membrane excitability that underlie time of day-related behavior $(68,69)$. Specific potassium channels have emerged as particularly relevant to time of day effects on neuronal excitability. In a discovery approach to the elucidation of circadian pacemaker mechanisms in Drosophila melanogaster, Ir, a gene encoding a protein that mediates an inward-rectifying potassium current was identified as playing a key role in regulating the excitability of pacemaker neurons (70). Reducing Ir expression in pacemaker neurons increased larval light avoidance and lengthened the period of adult locomotor rhythms, consistent with increased excitability, whereas increased Ir expression eliminated daily behavioral rhythms and dampened PER protein oscillations. Mutations and common variants of KCNJ10, the gene encoding the inward-rectifying potassium channel Kir4.1, are associated with rare and common forms of epilepsy, respectively (7174). Studies documenting the important role of Kir4.1 in the retina (75) and altered retinal function in epilepsy patients with KCNJ10 mutations (76) suggest a potential mechanistic link between circadian rhythms and epilepsy that deserves further examination.

Melatonin is the primary hormone integrating circadian rhythms and sleep/wake cycles, a role that it fulfills by directly regulating neuronal excitability. Melatonin receptors signal through $G$ protein-gated inwardly rectifying potassium (GIRK) channels in SCN neurons to regulate resting neuronal membrane potential via hyperpolarization (77). Melatonin receptor-linked GIRK channel activation in SCN neurons leads to phase advance (early sleep), and both GIRK2 protein expression and current amplitude oscillate over the sleep/wake cycle $(77,78)$. This suggests that the gene encoding GIRK2 (KCNJ6) is under 
clock control. Interestingly, GIRK2 deficient mice demonstrate increased susceptibility to chemically-induced seizures and even exhibit spontaneous generalized seizures (79). Conversely, activation of GIRK activity increases seizure latency and prevents convulsions in epileptic animals (80). GIRK channels have also been shown to be relevant to temporal lobe epilepsy (TLE). In one line of study, kainic acid-induced status epilepticus led to cleavage and dysfunction of GIRK1 and GIRK2 in rodent hippocampal tissue (81), further promoting hyperexcitability during the day, a period when individuals with TLE are most susceptible to having seizures (17). Thus, the relationship between GIRK and seizures may be bidirectional, both at the SCN and other neuronal populations.

The relationship between mechanisms of melatonin action and neuronal excitability related to seizures and epilepsy has received considerable attention. In animal models, the earliest studies show that melatonin inhibits expression of acute seizures induced by either GABA antagonists or glutamate agonists (82). These results are extended further by studies showing melatonin has anticonvulsant activity against hyperthermiainduced seizures and seizures induced by direct application of penicillin to the cerebral cortex $(83,84)$. It also decreases the frequency of spontaneous seizures arising after kainic acidinduced status epilepticus (85). Exogenous melatonin also has value as an adjunct to other anticonvulsants. Thus, it augments the anticonvulsant activity of phenobarbital in neonatal rats and of phenytoin and carbamazepine in mice $(86,87)$. Moreover, limbic epilepsy developing after status epilepticus induced by pilocarpine was significantly worse in rats that were pinealectomized, suggesting that melatonin deficiency facilitates epileptogenesis (88).

The anticonvulsant action of melatonin is mediated via specific melatonin receptors that control seizure threshold (89, 90). Further, the melatonin receptor agonist ramelteon possesses anticonvulsant effects and newer melatonin receptor drugs are under development (91-93). Clinical studies show that melatonin rhythm is normal in patients with epilepsy, but compared to control individuals, melatonin levels are low $(94,95)$. Thus, despite evidence that melatonin may be proconvulsant under some conditions, it is recognized as having potential therapeutic value in epilepsy and has been the focus of trials as an add-on therapy (96-98). In some cases, temporal clustering of seizures is in phase with the nocturnal rise in circulating melatonin, suggesting a potential difference between the physiologic role of endogenous melatonin and its action when administered as a drug (99). This idea is supported by a study in amygdalakindled rats in which melatonin was effective at reducing seizure frequency even though the highest after-discharge threshold (i.e., lowest seizure susceptibility) was in the morning when melatonin reached trough levels (100).

Studies in Drosophila and mouse clock neurons led to discovery of a general mechanism for circadian control of membrane excitability. It involves two distinct sets of ion channel systems: a system of sodium channels that is upregulated in the morning and that mediates wakefulness, and a system of potassium channels that is upregulated in the evening and that mediates sleep (101). Functional upregulation of BK potassium channels to dampen excitability occurs by reduction of channel inactivation in the mouse SCN (102). Critical sodium currents are regulated by the activation of glycogen synthase kinase 3 (GSK3), which itself is activated via phosphorylation in a circadian-dependent fashion and contributes to neuronal excitability through regulation of the persistent sodium current, INaP $(103,104)$. INaP exhibits a day/night difference in peak magnitude, and inhibition of GSK3 in the SCN suppresses persistent sodium current and reduces spontaneous firing rate of these neurons during the light (inactive) phase in rodents (104). The findings suggest that GSK3 activation of persistent sodium current channels reduce action potential hyperpolarization, which in turn increases SCN firing rate during the light (inactive) phase. Interestingly, chronic GSK3 activation increases neuronal firing during the dark (active phase). GSK3 also regulates phosphorylation of the core clock gene protein product BMAL1, thereby providing an important feedback mechanism for circadian control $(103,105)$. Given that GSK3 inactivation is reported to increase during the active phase (104), it is possible that abnormal GSK3 activation could contribute to daytime seizures.

The hippocampus is a brain region involved in many common forms of epilepsy, especially TLE, and hippocampal neurons are subject to circadian control in ways that are similar to the SCN (106). Like SCN neurons, circadian changes in membrane properties of hippocampal neurons are associated with cellular redox mechanisms that regulate ion channel function and alter synaptic activity (107). All of the core clock genes are expressed in the various subregions of the hippocampus; however, like other brain regions, cyclic expression of clock genes in hippocampus may have a smaller amplitude compared to SCN and for some genes occurs in antiphase (i.e., 180 degrees out of phase) (108-115). Similar to the SCN, core clock proteins such as BMAL1 in the hippocampus are under the circadian control of GSK3 (116).

The role of clock genes in the hippocampus is not fully understood; however, several potentially important observations have been made. For example, hippocampal mechanisms related to long-term potentiation are under circadian control, and molecular mechanisms related to circadian control of synaptic plasticity as related to memory formation are highly conserved over the course of evolution $(117,118)$. Clock mechanisms in the brain, including hippocampus, involve Rev-Erb $\alpha$ (NR1D1), a nuclear receptor expressed in all examined hippocampal subfields which represses the transcription of circadian oscillators $(119,120)$. Also, in the dentate gyrus, Per1 is linked to the process of neurogenesis (121). As mentioned previously, seizures experienced by patients with TLE tend to cluster during specific times of the day, suggesting a potential role for circadianassociated changes in hippocampal excitability (13).

Animal models support this concept. Analysis of slices prepared from rats killed at different points of the light/dark cycle reveal a larger steady-state amplitude of calcium current together with increased spike after-depolarization and slower adaptation of firing frequency after the start of the dark phase in CA3 neurons (122). Further, these changes were correlated with plasma levels of cortisol, a result consistent with a published 
clinical report showing higher cortisol levels are associated with greater seizure frequency in women with epilepsy being treated with anti-epileptic drugs $(122,123)$.

Although circadian effects on neuronal excitability of hippocampal neurons are well-documented, the specific events linking clock gene pathways to rhythmic changes in hippocampal synaptic activity, or to changes in the intrinsic properties of neuronal membranes, are not firmly established. Kcnal encodes the Kv1.1 voltage-gated potassium channel, which is highly expressed in pyramidal neurons of mouse hippocampus as well as in many other types of neurons. Mutant mice deficient in Kcnal exhibit a generalized seizure phenotype with diurnal periodicity and altered rest/activity rhythms (124). Electrophysiological study of hippocampal slices from epileptic Kcna1 knockout mice reveals that the intrinsic passive properties of CA3 pyramidal cells are normal but antidromic action potentials are recruited at lower thresholds (125). In the same study, synaptically-mediated long-latency epileptiform burst discharges were triggered by mossy fiber stimulation. Furthermore, there is a circadian periodicity to spontaneous seizures, with frequency peaking in the first $12 \mathrm{~h}$ of the $\mathrm{ZT}$ cycle (125). Interestingly, more seizures arise out of sleep in diurnal conditions, whereas under constant darkness, the majority occur out of the wakeful state (126). Together, these results suggest that loss of Kv1.1 from CA3 neuronal axons and terminals results in increased recurrent axon collateral excitability and the seizure phenotype of Kcna1 knockout mice (125). Also, of note, metabolism-based therapy with a ketogenic diet proved efficacious in lowering seizure frequency and restoring normal behavioral rhythms in this model (124).

A link between disrupted glial cell function and epilepsy has strong experimental support [reviewed in (127)]; therefore, circadian effects on glia may contribute to the timing of seizures in individual patients. Glial cells, including astrocytes, have been shown to regulate hippocampal processes, including synaptic transmission and excitability $(128,129)$, and to drive seizure threshold (130). TLE is often characterized by hippocampal sclerosis which includes synaptic reorganization, gliosis and neuronal loss (131). Astrocyte swelling associated with neuronal excitability is thought to occur through glial inwardly rectifying potassium channels (Kir channels) and water input via aquaporin-4 (AQP4) channels (132). Circadian and sleep/wake processes within astrocytes may also relate to time of day changes in excitability of hippocampal neurons. For example, diurnal changes in the expression and subcellular localization of brain fatty acid binding protein, Fabp7, occur in the hippocampus $(133,134)$. Fabp7 expression has been shown to increase in hippocampal astrocytes following kainic acid-induced seizures (135). Since Fabp7 expression is regulated by the circadian factors Rev-Erb $\alpha$ (136) and BMAL1 (137), and Rev-Erb $\alpha$ expression is affected by electroconvulsive seizure (138) while BMAL1 regulates seizure susceptibility (139), Fabp7 may represent a glial factor that contributes to epileptiform activity. Indeed, Fabp7 is known to control sleep/wake states in multiple species, including flies, mice, and humans (140, 141), therefore, Fabp7 expression in astrocytes may represent a functional node integrating neural activity, circadian rhythms and behavioral state.
Another neurotransmitter that links circadian rhythms and neuronal excitability is neuropeptide Y (NPY). This molecule is released by thalamic neurons, inducing phase advances in the SCN that are accompanied by suppression of PER2 and are mediated by long-term depression of neuronal excitability in a phase-specific manner (142). This is consistent with findings in other brain regions where NPY-induced persistent hyperpolarization underlies mechanisms of energy homeostasis, anxiety-related behavior, and thalamocortical synchronous firing, the latter being particularly relevant to the pathophysiology of absence epilepsy (143). PER2 expression is also dependent upon functional voltage-gated potassium channels including Kv4.2, which is encoded by KCND2, a gene that causes TLE when mutated $(144,145)$.

\section{DISRUPTION OF CORE CLOCK MECHANISMS: RELATION TO SEIZURES AND EPILEPSY}

It is recognized that the interaction between circadian rhythms and epilepsy is bidirectional, with alteration of clock mechanisms acting as a susceptibility factor for epilepsy, and seizures acting as disruptors of the internal clock. Evidence from an experimental animal model of TLE that develops following electrically-induced status epilepticus reveals a phase shift in circadian control of population spike firing rate during the latent phase of epileptogenesis, demonstrating directly that circadian effects on neuronal excitability are relevant to the development of seizures and epilepsy (146).

Daily photoperiod controls excitability of the brain as reflected by behavioral responses to experimental seizure stimuli. In mice treated with pentylenetetrazol, an acute photoperiod change from $12 \mathrm{~h} / 12 \mathrm{~h}$ to $18 \mathrm{~h} / 6 \mathrm{~h}$ light/dark cycle lowered seizure threshold, whereas decreasing the length of the light phase had no effect. On the other hand, chronic photoperiod alteration, either shorter or longer, decreased seizure threshold compared to animals maintained under a 12h/12h light/dark cycle (147). Further evidence comes from a study showing that maximal electroshock seizure threshold is lowest during the light (inactive) phase of the light/dark cycle, a time-dependent variation that was absent in Bmal1 knockout mice (139). Bmal1 knockout mice also exhibit significantly lower seizure thresholds compared to wild type littermates, suggesting a direct link between molecular clock mechanisms and seizure susceptibility, and implicating BMAL1 as an influence on neuronal excitability leading to seizures (139). It is noteworthy that Bmall knockout mice do not develop spontaneous seizures (i.e., epilepsy), suggesting that clock-related mechanisms function as susceptibility factors, providing a substrate upon which downstream factors interact to cause epilepsy. A corollary to this perspective is that clockcontrolled genes influence intracellular signaling, membrane potential, and subsequent neuronal firing patterns, all of which are highly relevant to seizure manifestation and development of epilepsy.

In addition to controlling susceptibility to acute seizures, BMAL1 also has a role in the process of epileptogenesis, as 
suggested by a study showing that the time course of the reduction in hippocampal Bmal1 expression in pilocarpinetreated rats parallels the development of spontaneous seizures (148). It is also likely that biomolecular mechanisms of epilepsy interacting with clock genes differ according to cellular subtype or brain region, given that different epilepsies are characterized by seizures that originate in distinct brain regions and occur at distinct points of the circadian cycle.

A possible means by which alteration in BMAL1 activity leads to seizures and epilepsy is via the mTOR pathway. Using a mouse model of tuberous sclerosis complex, a neurodevelopmental disorder involving epilepsy, in which the $T s c 1$ gene was conditionally deleted in forebrain, BMAL1 activity was shown to be upregulated in an mTOR-dependent manner and reduction of BMAL1 to control levels was able to rescue the mutant phenotype (149). BMAL1 also acts to regulate translation of mTOR protein, linking activity of the mTOR pathway with circadian rhythms (150). The mTOR pathway has been implicated previously as being highly relevant to the development and treatment of epilepsy (151).

Regulation of cellular metabolism may be another way by which BMAL1 controls seizure threshold. Defects in cellular energy metabolism are known to be causative in certain forms of epilepsy and the anti-epileptic effect of the ketogenic diet may be related to alteration of cellular energy metabolism pathways (152). Disruption of BMAL1 causes hypoinsulinemia, diabetes, and defects in synaptic vesicle assembly, which could affect neuronal excitability and lead to seizures (153). A search for BMAL1 target genes revealed many that encode central regulators of metabolic processes, further supporting the possibility that regulation of seizure threshold by BMAL1 is related to changes in the expression of genes controlling cellular energy homeostasis (154). Interestingly, another circadian factor, the transcription factor $\mathrm{D}$-albumin binding protein (DBP), affects hippocampal function and enhances seizure susceptibility via upregulation of glucagon-like peptide-1 receptor, a protein involved intimately in carbohydrate metabolism and cellular energy production $(155,156)$. Consistent with the findings on DBP/GLP-1 is evidence that glycogen in particular is an important energy molecule related directly to epilepsy (157). Relationships between BMAL1, seizure susceptibility and regulation of cell metabolism warrant further investigation with regards to the treatment of epilepsy.

A key protein interacting with BMAL1 is CLOCK, a molecule that is deficient in temporal lobe tissue from patients undergoing surgery for drug-refractory TLE (158). Deletion of the mouse Clock gene in cortical pyramidal neurons caused spontaneous epileptiform discharges in excitatory neurons associated with decreased inhibitory post-synaptic currents and decreased seizure threshold (158). The authors also report that the mutant mice have defects in dendritic spines similar to spine defects seen in human epileptogenic tissue. In a post-status epilepticus rat model, epileptogenesis is associated with loss of rhythmic expression of Clock transcripts and decreased levels of Clock transcripts at all ZTs studied, suggesting that Clock expression and neuronal activity in the hippocampus are linked (159). Subsequent study reveals that levels of Clock transcripts in hippocampus of pilocarpine-treated rats are not different from those in naive rats at early time-points after treatment, but at later time points they are significantly reduced, suggesting that decreasing Clock expression is involved in the process of epileptogenesis (148). Dysregulation of Clock expression parallels disturbance of spontaneous locomotor activity, indicating a possible role for seizure as a non-photic behavioral cue, possibly related to neuronal activity in the hippocampus (148).

Per1 is upregulated in the hippocampus following induction of experimental epilepsy, further evidence that seizures can perturb integral components of the clock (160). Clock mechanisms in extra-hippocampal brain regions are also perturbed by seizures. For example, one study showed that noise induces alteration of core clock gene expression in the inferior colliculus, a finding relevant to the elicitation of audiogenic seizures (161). Yet another study showed that electroconvulsive seizures in rats alter the expression of core clock genes in the frontal cortex (138). In the SCN, the time of day or ZT at which a seizure occurs has an influence on the rhythmicity of core clock gene expression and can also differentially affect sleep homeostasis (162). In the rat pilocarpine model, epileptic and naïve rats were compared at specific ZT points following the development of spontaneous seizures, with results showing that development of epilepsy is associated with alterations in rhythmic changes of all three period genes (Per1, Per2, and Per3) (159). In a subsequent study, Perl expression increased and Per 2 expression decreased at early time points after treatment, preceding the development of spontaneous seizures, whereas Per3 expression was unchanged (148). Neuronal death in the hippocampus CA1 region in an experimental stroke model is enhanced in Per1 knockout mice, a factor that may contribute to the risk for developing epilepsy following cerebrovascular insults (163). Overall, the strong bidirectional relationship between clock genes and seizures or epilepsy provides a compelling rationale for pursuing therapeutic strategies in this domain.

\section{CLOCK GENES AS CAUSATIVE OR RISK FACTORS FOR EPILEPSY}

Mutations in human clock-related genes cause syndromes that include epilepsy in the phenotype. Specifically, mutations in the $\mathrm{ROR} \alpha$ gene $(R O R A)$ link to a syndrome known as Intellectual Developmental Disorder with or without Epilepsy or Cerebellar ataxia [IDDECA (164)]. Whole exome sequencing identified RORA mutations in eleven IDDECA patients exhibiting developmental delay and autism spectrum symptoms, with or without epilepsy or ataxia (164). A consortium organized by the International League Against Epilepsy (ILAE) is generating whole exome sequence data on 25,000 individuals with common forms of human epilepsy and a subset of patients with less common forms of developmental epileptic encephalopathy (DEE). Known as Epi25K (http://epi-25.org/), the project will also generate dense single nucleotide polymorphism maps for use in genome wide association studies (GWAS). The Epi25K group and ILAE consortium published preliminary findings 
on the GWAS and rare variants in the expanding cohort $(165,166)$. The first analysis of rare variants in over 9,000 patients from Epi25K is available on the web (https://epi25. broadinstitute.org/), and results show that rare mutations are found in the RORA gene significantly more often in the DDE patients than in controls. On the other hand, RORA mutations are not found in excess in patients with common forms of generalized and focal epilepsy, consistent with the rare IDDECA phenotype.

It is noteworthy in this context that the causative mutation in the "staggerer" $(\mathrm{sg})$ mouse is a deletion in the RORA gene leading to defective Purkinje cell development in the cerebellum and an ataxic phenotype (167). Sg mice have spontaneous seizures, a finding consistent with the description of several rare human disorders in which development of epilepsy follows the development of ataxia, especially when the DNA polymerase gamma gene is mutated $(168,169)$. Thus, $R O R A$ gene mutations are linked to both ataxia and epilepsy in humans.

Similarly, mutations in the clock-related gene FBXL3 link to two rare disorders. The first includes intellectual developmental disorder with short stature, facial anomalies and speech defects (IDDSFAS) (170), although these patients do not suffer from seizures. The second is a form of Batten disease known as Ceroid Lipofuscinosis, Neuronal, 5 (CLN5) involving a defect in lysosomal storage and degradation of damaged or unwanted proteins. Batten disease leads to intellectual disability, ataxia, visual disturbance, and epilepsy (171). This form of Batten disease is caused by mutations in the CLN5 gene as well as mutations in FBXL3. Of interest is that these two genes overlap each other on chromosome 13 and transcribe from opposite DNA strands. Thus, it is possible that mutations found in CNL5 or FBXL3 could affect the expression or final function of either protein produced from this genomic region.

Mutations in PER2 and CRY1 result in advanced phase sleep disorder and delayed phase sleep disorder, respectively (172, 173); however, neither of these phenotypes includes epilepsy. Core clock genes including CLOCK, BMAL1, FBXL21, PER1, PER3, CRY1, and NR1D1 do not show evidence of harboring mutations that cause epilepsy in humans. Likewise, there is little evidence to date from human studies that genetic variations within core clock genes act as susceptibility factors for epilepsy. This is most likely because there has not been a systematic investigation of polymorphisms in the core clock genes in large populations of homogeneous epilepsy patients with respect to the timing or clustering of seizures. Large scale GWAS studies, such as the one being performed by ILAE, include tens of thousands of patients; however, these studies suffer from patient heterogeneity, possibly masking true genetic associations that have a small effect on phenotype. Common variants of CLOCK, PER2, and PER3 that had been associated with sleep disturbance were tested, but none showed association with JME in a cohort of $<100$ patients (174). Large scale GWAS with homogenous patient populations may reveal positive associations between core clock gene variations and epilepsy in the future, but for now, that hypothesis remains to be tested rigorously.
Although there is yet little evidence that core clock gene variants predispose or cause epilepsy, CLOCK RNA and protein are downregulated in brain tissue resected from patients with TLE (158). It is unclear if the downregulation is due to promoter variation at the CLOCK gene itself or is a result of variation in other non-core circadian genes. It is also unclear whether this finding reflects a disease process or is due to the impact of AEDs.

The gene whose variation appears to have the largest impact on the development of epilepsy is SCN1A, encoding Nav1.1, the major voltage-gated sodium channel expressed in CNS neurons. Deleterious SCN1A mutations cause uncommon monogenic forms of epilepsy, and common variants increase the risk for more typical sporadic forms of epilepsy $(166,175)$. Of note is the fact that Nav1.1 is critical for the oscillatory function of the SCN, possibly contributing to sleep disturbance mechanisms in patients with common or even uncommon forms of epilepsy (176). Additional evidence that sleep disturbance in epilepsy is due to underlying alteration of circadian rhythm, rather than a side effect of anti-epileptic drugs, comes from studies of a mouse model of Dravet syndrome, a severe DDE, in which it was shown that an Nav1.1 mutation causing reduced interneuron excitability and seizures also causes sleep impairment (177).

\section{CHRONOTHERAPY IN EPILEPSY}

Currently, regimens to treat a number of chronic medical conditions are beginning to apply concepts related to chronotherapy, including asthma $(178,179)$, hypertension $(180)$, and type 2 diabetes $(181,182)$. The premise of chronotherapy is to administer drugs (or other interventions) at strategic points of patients' circadian rhythms, particularly time periods when the chronic condition is most severe or when the drug would exhibit optimal bioavailability or effectiveness (183). For instance, in type 2 diabetes, long and short-acting insulin preparations are administered strategically, such that predictable fluctuations in diurnal and meal-based glucose levels are adequately covered (182).

As mentioned above, the ability to predict the time period when it is most likely for an individual with a specific type of epilepsy to experience a seizure has opened up the possibility of utilizing chronotherapy to enhance the effectiveness of treatment for many people with epilepsy. The viability of chronotherapeutic strategies to optimize the efficacy of anti-epileptic drug (AED) treatment is supported by both clinical and basic research. In a study with rodents, the anti-convulsant efficacy of valproic acid varied as a function of the time in which it was administered (184). Though valproic acid increased the latency to the first pentylnetetrazol-induced seizure at all time points, the highest and lowest increases were observed when the drug was administered 7 and $19 \mathrm{~h}$ after light onset, respectively. The authors reasoned that these effects may have been influenced by circadian variation in drug disposition. For instance, some studies have found that drug clearance is greatest 
during dark exposure while others indicate that absorption of valproate is substantially delayed if taken after consuming a meal (14).

Results from human AED chronotherapy studies indicate direct clinical relevance. In one study, adults suffering from nighttime tonic-clonic seizures demonstrated improved seizure control and reduced side effects when a greater percentage of the daily divided dosage of phenytoin and carbamazepine was administered in the evening (185). By shifting the administration of AEDs from earlier in the day to 20:00, therapeutic drug levels were more readily achieved. This practice of uneven drug distribution is known as differential dosing. When children suffering from nighttime or early morning seizures were dosed differentially, such that the evening dose was twice that of the morning dose, at least a $50 \%$ reduction in seizure frequency was observed in $88 \%$ of patients (186). In another study with nighttime seizure patients, the differential dosing of clobazam (i.e., greater than half of the daily dosage was taken after 18:00) led to a median seizure reduction of $75 \%$ compared to a seizure reduction of $50 \%$ for the evenly dosed control group (187). Interestingly, the differentially dosed group also tolerated a higher total dose than the control group in terms of adverse effects.

An important consideration with regard to chronotherapy is patient chronotype (i.e., whether the individual is more morning or evening-oriented). Since people with evening chronotypes tend to go to bed later, their biological oscillating mechanisms (including those generating products that modulate seizure threshold/susceptibility) are likely shifted. That is, at 6:00 AM, the morning TLE patient will have different levels of relevant clock products than the evening TLE patient (as they are on different circadian times). For this reason, it may be reasonable to shift the recommended AED administration time according to the patient's chronotype and not base it on a specific time of day. Further, one study found that patients adapt self-administration of AEDs to their chronotype (188). Morningoriented patients would often self-administer medications well before the recommended 8:00 time, whereas eveningoriented patients would often do so well after 8:00. The latter was especially true during "off days" (i.e., weekends, holidays), when the evening patients slept extra late in order to reduce their sleep debt. Therefore, an additional benefit of shifting AED dosing to later in the day is increased consistency of medication timing. This concept is illustrated in Figure 3.

In developing chronotherapeutic strategies in epilepsy, it is important to consider that seizures may influence chronotype. Thus, patients experiencing generalized seizures were 5 times more likely to have a late chronotype than healthy controls, and epilepsy patients do not appear to demonstrate the normal positive correlation between age and morning-proclivity (189). The former finding is interesting, given that the evening-heavy differential dose intervention employed by Thome-Souza et al. (187) was of most benefit to patients suffering from generalized seizures. However, genetic factors also influence chronotype, and so physicians must balance therapeutic regimens with promotion of healthy lifestyle decisions (e.g., preventing the sleep deprivation and circadian misalignment prevalent in eveningoriented individuals).

Applying chronotherapy to the management of epilepsy appears to be a prudent undertaking, particularly for patients with highly predictable seizure patterns or severe, drug-resistant epilepsy. Since every patient with epilepsy is unique, this practice would need to be patient specific. However, further research is required to better characterize the effects of chronotherapeutic approaches on all types of seizures and epileptic conditions. For instance, it may be useful to determine whether differential dosing favoring daytime AED administration enhances seizure suppression in patients that commonly experience focal seizures from the temporal lobe, since these seizures more frequently occur during the daytime and wakefulness. Interestingly, several recent studies suggest that certain biological mechanisms that change cellular redox state also correlate with neuronal excitability, and that many of these mechanisms occur in a circadian manner $(68,69)$. Indeed, diminished neuronal activity at night correlates with an electrochemically reduced intracellular state (69). Perhaps circadian variability in redox state may explain why seizures in TLE tend to occur during the day.

\section{LIMITATIONS}

We accepted several limitations in the development of this review. One limitation was that our literature search did not include non-English language studies, and so it is possible that certain important information was omitted. Another limitation was that our literature search focused purely on peer-reviewed publications and did not consider information from dissertations, abstracts, or presentations at scientific conferences. Also, we did not include every relevant research study, but rather focused critical assessment on the most impactful work. Our literature review relied most heavily on the Pubmed database and we placed the greatest emphasis on studies published over the past decade. Our search strategy combined the terms "seizure," "epilepsy" and "neuronal excitability" with the terms "circadian," "diurnal," "time of day," and "sleep." Overall, while our presentation encompasses the most relevant research conducted over the past decade, the approach we used to develop it did not fulfill journal criteria for a comprehensive systematic review.

\section{SUMMARY}

Despite the armamentarium of available treatments for epilepsy, many patients still experience variable numbers of seizures, some on a daily basis. Many factors influence the time of day at which a seizure will occur in a given individual with epilepsy, and some of these factors directly involve mechanisms that mediate circadian rhythms. Elucidation of genetic expression pathways underlying the oscillating function of SCN neurons, 


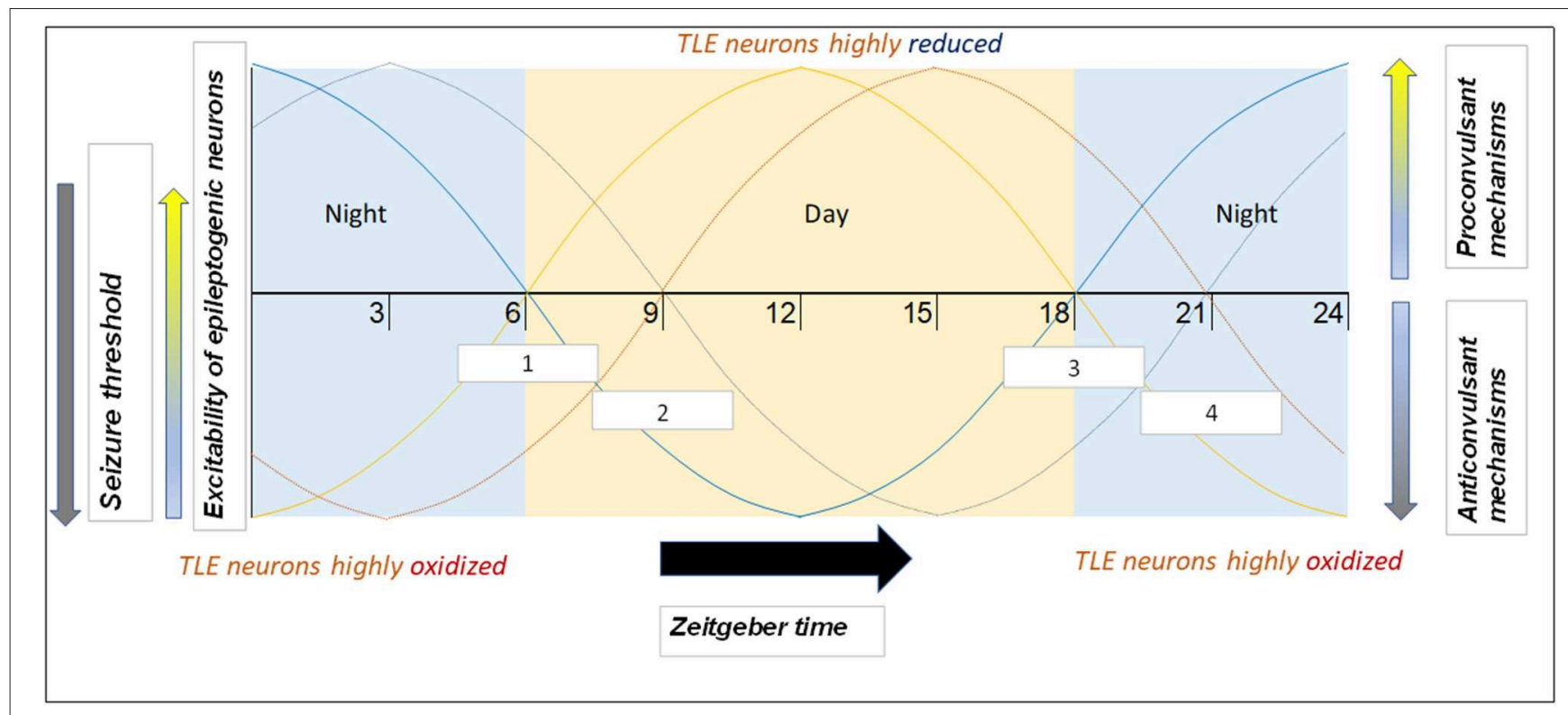

FIGURE 3 | Example of how phenotype and chronotype permit implementation of chronotherapy for epilepsy, along with potential mechanisms responsible for time-based seizure susceptibility. This depiction portrays likely patient circadian (daily) seizure threshold/neuronal excitability patterns. Zeitgeber times are on the x-axis. Of the four "sample patients" illustrated, two have a morning chronotype (morning larks; curves depicted in lighter hues) and two have an evening chronotype (night owls; curves depicted in darker hues). Two suffer from focal seizures originating in the temporal lobe (orange hues) and seizures in the two others originate in the frontal lobe (blue hues). Since seizures are most likely to occur during the mid-day (12-15) and night (24-3) for temporal and frontal lobe epilepsies, respectively (9), therapeutic drugs may be best suited to be administered soon before the high seizure tendency time window (white boxes). Boxes 1 and 2 (corresponding to light orange and dark orange curves, respectively) represent AED time administration windows for TLE patients with morning and evening chronotypes, respectively. Boxes 3 and 4 (corresponding to light blue and dark blue curves, respectively) represent time windows for frontal lobe epilepsy (FLE) patients with morning and evening chronotypes, respectively.

and the study of parallel pathways in epileptogenic regions of the brain (e.g., hippocampus, cerebral cortex), provides a basis for understanding links between circadian rhythms and seizures or epilepsy at the molecular level. In particular, the overlapping roles of specific ion channel proteins, both as determinants of SCN neuronal function and as susceptibility or causative factors for seizures and epilepsy, suggests potential approaches to the development of new anti-epilepsy treatment regimens. Mutations in certain ion channel genes important for SCN function, such as SCN1A and KCNJ10, are wellknown to strongly associate with epilepsy phenotypes in humans, and have served for many years as leads for AED development without great success. However, a more complete understanding of how such genes interact with circadian factors could provide means to better exploit them as a source of druggable targets.

A critical link between circadian rhythms and expression of seizures relates to oscillations in the excitability of neuronal membranes. Cyclic expression of core clock genes in SCN neurons is synced with an oscillating pattern of membrane excitability, and testing whether similar core clock gene expression generates excitability oscillations in neurons from other brain regions will be important for determining their potential role in regulating circadian seizure susceptibility. For example, extra-SCN brain regions show molecular and cellular/neurophysiological rhythms that may be under autonomous control (190). Isolated hippocampal slice cultures from mPer2luc transgenic reporter mice show that PER2::LUC expression continues to persist over several circadian cycles (113), which could relate to circadian changes in hippocampal electrophysiology (117). In this way, vulnerable neurons in epileptogenic brain foci may be triggered to fire action potentials inappropriately, thereby initiating a seizure, at times when circadian-dependent membrane excitability is at a peak level. Whether SCN oscillations regulate circadian gene expression and electrophysiological properties of hippocampal or cortical neurons is poorly understood and remains an important area of future investigation. Deeper insight into the interaction between oscillatory neuronal activity in the SCN and the biophysical properties of epileptogenic neurons will lead potentially to the identification of novel AED targets and to the development of new medicines. In addition, development of detailed patient chronotypes, including comprehensive evaluation of the timing of seizure occurrence, may serve as a means to personalize therapy for people with epilepsy. This will not only facilitate the development of new drugs designed to target novel molecules identified at interface between circadian rhythms, neuronal excitability, and seizures, but will also lead to an increase in effectiveness of treatments that are currently available. Overall, further research into the 
relationship between circadian rhythms and epilepsy has the potential to lead to novel treatment strategies that could benefit many patients.

\section{AUTHOR CONTRIBUTIONS}

$\mathrm{CR}$ and $\mathrm{AB}$ performed the majority of the work including creation of figures. JG contributed oversight to the writing of sections Disruption of Core Clock Mechanisms: Relation to Seizures and Epilepsy, Clock Genes as Causative or Risk Factors for Epilepsy, Chronotherapy in Epilepsy, Limitations, and Summary. RB wrote the section Clock Genes As Causative or

\section{REFERENCES}

1. Panda S, Hogenesch JB, Kay SA. Circadian rhythms from flies to human. Nature. (2002) 417:329-35. doi: 10.1038/417329a

2. Hastings MH, Reddy AB, Maywood ES. A clockwork web: circadian timing in brain and periphery, in health and disease. Nat Rev Neurosci. (2003) 4:649-61. doi: 10.1038/nrn1177

3. Scharfman HE. The neurobiology of epilepsy. Curr Neurol Neurosci Rep. (2007) 7:348-54. doi: 10.1007/s11910-007-0053-Z

4. Pitkanen A, Lukasiuk K. Mechanisms of epileptogenesis and potential treatment targets. Lancet Neurol. (2011) 10:173-86. doi: 10.1016/S1474-4422(10)70310-0

5. Fisher RS, Acevedo C, Arzimanoglou A, Bogacz A, Cross JH, Elger CE, et al. ILAE official report: a practical clinical definition of epilepsy. Epilepsia. (2014) 55:475-82. doi: 10.1111/epi.12550

6. Quigg M. Circadian rhythms: interactions with seizures and epilepsy. Epilepsy Res. (2000) 42:43-55. doi: 10.1016/S0920-1211(00)00157-1

7. Karoly PJ, Goldenholz DM, Freestone DR, Moss RE, Grayden DB, Theodore WH, et al. Circadian and circaseptan rhythms in human epilepsy: a retrospective cohort study. Lancet Neurol. (2018) 17:977-85. doi: 10.1016/S1474-4422(18)30274-6

8. Durazzo TS, Spencer SS, Duckrow RB, Novotny EJ, Spencer DD, Zaveri HP. Temporal distributions of seizure occurrence from various epileptogenic regions. Neurology. (2008) 70:1265-71. doi: 10.1212/01.wnl.0000308938.84918.3f

9. Gurkas E, Serdaroglu A, Hirfanoglu T, Kartal A, Yilmaz U, Bilir E. Sleepwake distribution and circadian patterns of epileptic seizures in children. Eur J Paediatr Neurol. (2016) 20:549-54. doi: 10.1016/j.ejpn.2016.04.004

10. Hofstra WA, Spetgens WP, Leijten FS, van Rijen PC, Gosselaar P, van der Palen J, et al. Diurnal rhythms in seizures detected by intracranial electrocorticographic monitoring: an observational study. Epilepsy Behav. (2009) 14:617-21. doi: 10.1016/j.yebeh.2009.01.020

11. Hofstra WA, Gordijn MC, van der Palen J, van Regteren R, Grootemarsink $\mathrm{BE}$, de Weerd AW. Timing of temporal and frontal seizures in relation to the circadian phase: a prospective pilot study. Epilepsy Res. (2011) 94:158-62. doi: 10.1016/j.eplepsyres.2011.01.015

12. Karafin M, St Louis EK, Zimmerman MB, Sparks JD, Granner MA. Bimodal ultradian seizure periodicity in human mesial temporal lobe epilepsy. Seizure. (2010) 19:347-51. doi: 10.1016/j.seizure.2010.05.005

13. Nzwalo H, Menezes Cordeiro I, Santos AC, Peralta R, Paiva T, Bentes C. 24-hour rhythmicity of seizures in refractory focal epilepsy. Epilepsy Behav. (2016) 55:75-8. doi: 10.1016/j.yebeh.2015.12.005

14. Ramgopal S, Thome-Souza S, Loddenkemper T. Chronopharmacology of anti-convulsive therapy. Curr Neurol Neurosci Rep. (2013) 13:339. doi: 10.1007/s11910-013-0339-2

15. Ramgopal S, Powell C, Zarowski M, Alexopoulos AV, Kothare SV, Loddenkemper T. Predicting diurnal and sleep/wake seizure patterns in paediatric patients of different ages. Epileptic Disord. (2014) 16:56-66. doi: 10.1684/epd.2014.0644
Risk Factors for Epilepsy and also contributed to other sections on the description of epilepsy and epilepsy seizure patterns. TF participated in the writing and editing of all sections and provided oversight to the entire project.

\section{FUNDING}

This work was supported by NIH grants NIGMS R35GM133440 (JG) and NINDS R21NS095756-01 (TF, RB). It was also supported by institutional funds from Cooper Medical School of Rowan University, and a grant from the Camden Research Health Initiative (TF).

16. Loddenkemper T, Vendrame M, Zarowski M, Gregas M, Alexopoulos AV, Wyllie E, et al. Circadian patterns of pediatric seizures. Neurology. (2011) 76:145-53. doi: 10.1212/WNL.0b013e318206ca46

17. Zarowski $\mathrm{M}$, Loddenkemper $\mathrm{T}$, Vendrame $\mathrm{M}$, Alexopoulos $\mathrm{AV}$, Wyllie E, Kothare SV. Circadian distribution and sleep/wake patterns of generalized seizures in children. Epilepsia. (2011) 52:1076-83. doi: 10.1111/j.1528-1167.2011.03023.x

18. Gigli GL, Calia E, Marciani MG, Mazza S, Mennuni G, Diomedi M, et al. Sleep microstructure and EEG epileptiform activity in patients with juvenile myoclonic epilepsy. Epilepsia. (1992) 33:799-804. doi: 10.1111/j.1528-1157.1992.tb02184.x

19. Goldenholz DM, Rakesh K, Kapur K, Gainza-Lein M, Hodgeman R, Moss R, et al. Different as night and day: patterns of isolated seizures, clusters, and status epilepticus. Epilepsia. (2018) 59:e73-7. doi: 10.1111/epi.14076

20. Yamaguchi H, Nagase H, Ishida Y, Toyoshima D, Maruyama A, Tomioka $\mathrm{K}$, et al. Diurnal occurrence of complex febrile seizure and their severity in pediatric patients needing hospitalization. Epilepsy Behav. (2018) 80:280-4. doi: 10.1016/j.yebeh.2018.01.015

21. Sanchez Fernandez I, Gainza-Lein M, Abend NS, Amengual-Gual M, Anderson A, Arya R, et al. The onset of pediatric refractory status epilepticus is not distributed uniformly during the day. Seizure. (2019) 70:90-6. doi: $10.1016 /$ j.seizure.2019.06.017

22. Seneviratne U, Lai A, Cook M, D'Souza W, Boston RC. "Sleep Surge": the impact of sleep onset and offset on epileptiform discharges in idiopathic generalized epilepsies. Clin Neurophysiol. (2020) 131:1044-50. doi: 10.1016/j.clinph.2020.01.021

23. Punia V, Bena J, Krishnan B, Newey C, Hantus S. New onset epilepsy among patients with periodic discharges on continuous electroencephalographic monitoring. Epilepsia. (2018) 59:1612-20. doi: 10.1111/epi. 14509

24. Pressler RM, Robinson RO, Wilson GA, Binnie CD. Treatment of interictal epileptiform discharges can improve behavior in children with behavioral problems and epilepsy. J Pediatr. (2005) 146:112-7. doi: 10.1016/j.jpeds.2004.08.084

25. Del Felice A, Arcaro C, Storti SF, Fiaschi A, Manganotti P. Slow spindles' cortical generators overlap with the epileptogenic zone in temporal epileptic patients: an electrical source imaging study. Clin Neurophysiol. (2013) 124:2336-44. doi: 10.1016/j.clinph.2013.06.002

26. Engel J Jr, Bragin A, Staba R. Nonictal EEG biomarkers for diagnosis and treatment. Epilepsia Open. (2018) 3(Suppl 2):120-6. doi: 10.1002/epi4.12233

27. Niedermeyer E. Primary (Idiopathic) generalized epilepsy and underlying mechanisms. Clin Electroencephalogr. (1996) 27:1-21. doi: $10.1177 / 155005949602700103$

28. Tezer FI, Remi J, Erbil N, Noachtar S, Saygi S. A reduction of sleep spindles heralds seizures in focal epilepsy. Clin Neurophysiol. (2014) 125:2207-11. doi: 10.1016/j.clinph.2014.03.001

29. Yu-Dan L, Zan W, Ma DH, Meng HM, Cui L. Association between epileptiform discharges and the sleep cycle in 200 epileptic patients. Int $J$ Neurosci. (2013) 123:196-203. doi: 10.3109/00207454.2012.746334 
30. Seneviratne U, Cook MJ, D'Souza WJ. Electroencephalography in the diagnosis of genetic generalized epilepsy syndromes. Front Neurol. (2017) 8:499. doi: 10.3389/fneur.2017.00499

31. Geyer JD, Carney PR, Gilliam F. Focal epileptiform spikes in conjuction with K-complexes. J Clin Neurophysiol. (2006) 23:436-9. doi: 10.1097/01.wnp.0000228499.92313.d6

32. Mak-McCully RA, Deiss SR, Rosen BQ, Jung KY, Sejnowski TJ, Bastuji H, et al. Synchronization of isolated downstates (K-complexes) may be caused by cortically-induced disruption of thalamic spindling. PLoS Comput Biol. (2014) 10:e1003855. doi: 10.1371/journal.pcbi.1003855

33. Halasz P, Bodizs R, Ujma PP, Fabo D, Szucs A. Strong relationship between NREM sleep, epilepsy and plastic functions - a conceptual review on the neurophysiology background. Epilepsy Res. (2019) 150:95-105. doi: 10.1016/j.eplepsyres.2018.11.008

34. Fan D, Liao F, Wang Q. The pacemaker role of thalamic reticular nucleus in controlling spike-wave discharges and spindles. Chaos. (2017) 27:073103. doi: 10.1063/1.4991869

35. Sitnikova E, Grubov V, Hramov AE. Slow-wave activity preceding the onset of 10-15-Hz sleep spindles and 5-9-Hz oscillations in electroencephalograms in rats with and without absence seizures. J Sleep Res. (2019) e12927. doi: $10.1111 /$ jsr.12927

36. Kozák G, Földi T, Berényi A. Spike-and-wave discharges are not pathological sleep spindles, network-level aspects of age-dependent absence seizure development in rats. eNeuro. (2020). 7:ENEURO.0253-0219.2019. doi: 10.1523/ENEURO.0253-19.2019

37. Englot DJ, Mishra AM, Mansuripur PK, Herman P, Hyder F, Blumenfeld H. Remote effects of focal hippocampal seizures on the rat neocortex. J Neurosci. (2008) 28:9066-81. doi: 10.1523/JNEUROSCI.2014-08.2008

38. Englot DJ, Yang L, Hamid H, Danielson N, Bai X, Marfeo A, et al. Impaired consciousness in temporal lobe seizures: role of cortical slow activity. Brain. (2010) 133:3764-77. doi: 10.1093/brain/awq316

39. Yue Z, Freedman IG, Vincent P, Andrews JP, Micek C, Aksen M, et al. Up and down states of cortical neurons in focal limbic seizures. Cerebral Cortex. (2019) 30:3074-86. doi: 10.1093/cercor/bhz295

40. Tinuper P, Bisulli F, Cross JH, Hesdorffer D, Kahane P, Nobili L, et al. Definition and diagnostic criteria of sleep-related hypermotor epilepsy. Neurology. (2016) 86:1834-42. doi: 10.1212/WNL.0000000000002666

41. Gibbs SA, Proserpio P, Francione S, Mai R, Cossu M, Tassi L, et al. Seizure duration and latency of hypermotor manifestations distinguish frontal from extrafrontal onset in sleep-related hypermotor epilepsy. Epilepsia. (2018) 59:e130-4. doi: 10.1111/epi.14517

42. Crino PB. Focal cortical dysplasia. Semin Neurol. (2015) 35:201-8. doi: 10.1055/s-0035-1552617

43. Baldassari S, Ribierre T, Marsan E, Adle-Biassette H, Ferrand-Sorbets $\mathrm{S}$, Bulteau C, et al. Dissecting the genetic basis of focal cortical dysplasia: a large cohort study. Acta Neuropathol. (2019) 138:885-900. doi: 10.1007/s00401-019-02061-5

44. Kumar J, Solaiman A, Mahakkanukrauh P, Mohamed R, Das S. Sleep related epilepsy and pharmacotherapy: an insight. Front Pharmacol. (2018) 9:1088. doi: 10.3389/fphar.2018.01088

45. Licchetta L, Pippucci T, Baldassari S, Minardi R, Provini F, Mostacci B, et al. Sleep-related hypermotor epilepsy (SHE): contribution of known genes in 103 patients. Seizure. (2020) 74:60-4. doi: 10.1016/j.seizure.2019.11.009

46. Becchetti A, Aracri P, Meneghini S, Brusco S, Amadeo A. The role of nicotinic acetylcholine receptors in autosomal dominant nocturnal frontal lobe epilepsy. Front Physiol. (2015) 6:22. doi: 10.3389/fphys.2015.00022

47. Asioli GM, Rossi S, Bisulli F, Licchetta L, Tinuper P, Provini F. Therapy in Sleep-Related Hypermotor Epilepsy (SHE). Curr Treat Options Neurol. (2020) 22:1. doi: 10.1007/s11940-020-0610-1

48. Menghi V, Bisulli F, Tinuper P, Nobili L. Sleep-related hypermotor epilepsy: prevalence, impact and management strategies. Nat Sci Sleep. (2018) 10:31726. doi: 10.2147/NSS.S152624

49. Golombek DA, Rosenstein RE. Physiology of circadian entrainment. Physiol Rev. (2010) 90:1063-102. doi: 10.1152/physrev.00009.2009

50. Yoo SH, Yamazaki S, Lowrey PL, Shimomura K, Ko CH, Buhr ED, et al. PERIOD2::LUCIFERASE real-time reporting of circadian dynamics reveals persistent circadian oscillations in mouse peripheral tissues. Proc Natl Acad Sci USA. (2004) 101:5339-46. doi: 10.1073/pnas.0308709101
51. Brown RE, Basheer R, McKenna JT, Strecker RE, McCarley RW. Control of sleep and wakefulness. Physiol Rev. (2012) 92:1087-187. doi: 10.1152/physrev.00032.2011

52. Kroeger D, Absi G, Gagliardi C, Bandaru SS, Madara JC, Ferrari LL, et al. Galanin neurons in the ventrolateral preoptic area promote sleep and heat loss in mice. Nat Commun. (2018) 9:4129. doi: 10.1038/s41467-018-06590-7

53. Suntsova N, Guzman-Marin R, Kumar S, Alam MN, Szymusiak R, McGinty D. The median preoptic nucleus reciprocally modulates activity of arousalrelated and sleep-related neurons in the perifornical lateral hypothalamus. $J$ Neurosci. (2007) 27:1616-30. doi: 10.1523/JNEUROSCI.3498-06.2007

54. Saper CB, Fuller PM, Pedersen NP, Lu J, Scammell TE. Sleep state switching. Neuron. (2010) 68:1023-42. doi: 10.1016/j.neuron.2010.11.032

55. Carlson N. Physiology of Behavior. Upper Saddle River, NJ: Pearson (2013).

56. Karatsoreos IN, Silver R. Chapter 27 - Body clocks in health and disease. In: Conn PM, editor. Conn's Translational Neuroscience. San Diego, CA: Academic Press (2017). p. 599-615.

57. Eban-Rothschild A, Bloch G. Social influences on circadian rhythms and sleep in insects. Adv Genet. (2012) 77:1-32. doi: 10.1016/B978-0-12-387687-4.00001-5

58. Voigt RM, Forsyth CB, Green SJ, Engen PA, Keshavarzian A. Circadian rhythm and the gut microbiome. Int Rev Neurobiol. (2016) 131:193-205. doi: 10.1016/bs.irn.2016.07.002

59. Cox KH, Takahashi JS. Circadian clock genes and the transcriptional architecture of the clock mechanism. J Mol Endocrinol. (2019) 63:R93-102. doi: 10.1530/JME-19-0153

60. Mavroudis PD, DuBois DC, Almon RR, Jusko WJ. Modeling circadian variability of core-clock and clock-controlled genes in four tissues of the rat. PLoS ONE. (2018) 13:e0197534. doi: 10.1371/journal.pone.0197534

61. Herzog ED. Neurons and networks in daily rhythms. Nat Rev Neurosci. (2007) 8:790-802. doi: 10.1038/nrn2215

62. Wagner S, Sagiv N, Yarom, Y. GABA-induced current and circadian regulation of chloride in neurones of the rat suprachiasmatic nucleus. $J$ Physiol. (2001) 537(Pt. 3):853-69. doi: 10.1113/jphysiol.2001.012743

63. Ono D, Honma KI, Yanagawa Y, Yamanaka A, Honma S. Role of GABA in the regulation of the central circadian clock of the suprachiasmatic nucleus. J Physiol Sci. (2018) 68:333-43. doi: 10.1007/s12576-018-0604-x

64. Itri J, Michel S, Waschek JA, Colwell CS. Circadian rhythm in inhibitory synaptic transmission in the mouse suprachiasmatic nucleus. J Neurophysiol. (2004) 92:311-9. doi: 10.1152/jn.01078.2003

65. Ye H, Kaszuba S. Inhibitory or excitatory? Optogenetic interrogation of the functional roles of GABAergic interneurons in epileptogenesis. J Biomed Sci. (2017) 24:93. doi: 10.1186/s12929-017-0399-8

66. Li Q, Li Y, Wang X, Qi J, Jin X, Tong H, et al. Fbxl4 serves as a clock output molecule that regulates sleep through promotion of rhythmic degradation of the GABAA receptor. Curr Biol. (2017) 27:3616-25.e3615. doi: 10.1016/j.cub.2017.10.052

67. El-Hattab AW, Dai H, Almannai M, Wang J, Faqeih EA, Al Asmari A, et al. Molecular and clinical spectra of FBXL4 deficiency. Hum Mutat. (2017) 38:1649-59. doi: 10.1002/humu.23341

68. Wang TA, Yu YV, Govindaiah G, Ye X, Artinian L, Coleman TP, et al. Circadian rhythm of redox state regulates excitability in suprachiasmatic nucleus neurons. Science. (2012) 337:839-42. doi: 10.1126/science.1222826

69. Bothwell MY, Gillette MU. Circadian redox rhythms in the regulation of neuronal excitability. Free Radic Biol Med. (2018) 119:45-55. doi: 10.1016/j.freeradbiomed.2018.01.025

70. Ruben M, Drapeau MD, Mizrak D, Blau J. A mechanism for circadian control of pacemaker neuron excitability. J Biol Rhythms. (2012) 27:353-64. doi: $10.1177 / 0748730412455918$

71. Bockenhauer D, Feather S, Stanescu HC, Bandulik S, Zdebik AA, Reichold $\mathrm{M}$, et al. Epilepsy, ataxia, sensorineural deafness, tubulopathy, and KCNJ10 mutations. N Engl J Med. (2009) 360:1960-70. doi: 10.1056/NEJMoa0810276

72. Scholl UI, Choi M, Liu T, Ramaekers VT, Häusler MG, Grimmer $\mathrm{J}$, et al. Seizures, sensorineural deafness, ataxia, mental retardation, and electrolyte imbalance (SeSAME syndrome) caused by mutations in andlt;emandgt;KCNJ10andlt;/emandgt. Proc Natl Acad Sci USA. (2009) 106:5842. doi: 10.1073/pnas.0901749106

73. Buono RJ, Lohoff FW, Sander T, Sperling MR, O'Connor MJ, Dlugos $\mathrm{DJ}$, et al. Association between variation in the human $\mathrm{KCNJ} 10$ potassium 
ion channel gene andseizure susceptibility. Epilepsy Res. (2004) 58:175-83. doi: 10.1016/j.eplepsyres.2004.02.003

74. Heuser K, Nagelhus EA, Taubøll E, Indahl U, Berg PR, Lien S, et al. Variants of the genes encoding AQP4 and Kir4.1 are associated with subgroups of patients with temporal lobe epilepsy. Epilepsy Res. (2010) 88:55-64. doi: 10.1016/j.eplepsyres.2009.09.023

75. Connors NC, Kofuji, P. Potassium channel Kir4.1 macromolecular complex in retinal glial cells. Glia. (2006) 53:124-31. doi: 10.1002/glia.20271

76. Thompson DA, Feather S, Stanescu HC, Freudenthal B, Zdebik AA, Warth R, et al. Altered electroretinograms in patients with KCNJ10 mutations and EAST syndrome. J Physiol. (2011) 589:1681-9. doi: 10.1113/jphysiol.2010.198531

77. Hablitz LM, Molzof HE, Abrahamsson KE, Cooper JM, Prosser RA, Gamble KL. GIRK Channels mediate the nonphotic effects of exogenous melatonin. J Neurosci. (2015) 35:14957-65. doi: 10.1523/JNEUROSCI.1597-15.2015

78. Pizarro A, Hayer K, Lahens NF, Hogenesch JB. CircaDB: a database of mammalian circadian gene expression profiles. Nucleic Acids Res. (2013) 41:D1009-13. doi: 10.1093/nar/gks1161

79. Signorini S, Liao YJ, Duncan SA, Jan LY, Stoffel M. Normal cerebellar development but susceptibility to seizures in mice lacking $\mathrm{G}$ protein-coupled, inwardly rectifying K+ channel GIRK2. Proc Natl Acad Sci USA. (1997) 94:923-7. doi: 10.1073/pnas.94.3.923

80. Kaufmann K, Romaine I, Days E, Pascual C, Malik A, Yang L, et al. ML297 (VU0456810), the first potent and selective activator of the GIRK potassium channel, displays antiepileptic properties in mice. ACS Chem Neurosci. (2013) 4:1278-86. doi: 10.1021/cn400062a

81. Baculis BC, Weiss AC, Pang W, Jeong HG, Lee JH, Liu DC, et al. Prolonged seizure activity causes caspase dependent cleavage and dysfunction of Gprotein activated inwardly rectifying potassium channels. Sci Rep. (2017) 7:12313. doi: 10.1038/s41598-017-12508-y

82. Lapin IP, Mirzaev SM, Ryzov IV, Oxenkrug GF. Anticonvulsant activity of melatonin against seizures induced by quinolinate, kainate, glutamate, NMDA, pentylenetetrazole in mice. J Pineal Res. (1998) 24:215-8. doi: 10.1111/j.1600-079X.1998.tb00535.x

83. Aydin L, Gundogan NU, Yazici C. Anticonvulsant efficacy of melatonin in an experimental model of hyperthermic febrile seizures. Epilepsy Res. (2015) 118:49-54. doi: 10.1016/j.eplepsyres.2015.11.004

84. Yildirim M, Marangoz C. Anticonvulsant effects of melatonin on penicillininduced epileptiform activity in rats. Brain Res. (2006) 1099:183-8. doi: 10.1016/j.brainres.2006.04.093

85. Petkova Z, Tchekalarova J, Pechlivanova D, Moyanova S, Kortenska L, Mitreva R, et al. Treatment with melatonin after status epilepticus attenuates seizure activity and neuronal damage but does not prevent the disturbance in diurnal rhythms and behavioral alterations in spontaneously hypertensive rats in kainate model of temporal lobe epilepsy. Epilepsy Behav. (2014) 31:198-208. doi: 10.1016/j.yebeh.2013.12.013

86. Forcelli PA, Soper C, Duckles A, Gale K, Kondratyev A. Melatonin potentiates the anticonvulsant action of phenobarbital in neonatal rats. Epilepsy Res. (2013) 107:217-23. doi: 10.1016/j.eplepsyres.2013.09.013

87. Gupta YK, Gupta M, Chaudhary G, Kohli K. Modulation of antiepileptic effect of phenytoin and carbamazepine by melatonin in mice. Methods Find Exp Clin Pharmacol. (2004) 26:99-102. doi: 10.1358/mf.2004.26.2. 800061

88. de Lima E, Soares JM Jr, del Carmen Sanabria Garrido Y, Gomes Valente S, Priel MR, Chada Baracat E, et al. Effects of pinealectomy and the treatment with melatonin on the temporal lobe epilepsy in rats. Brain Res. (2005) 1043:24-31. doi: 10.1016/j.brainres.2005.02.027

89. Stewart LS, Leung LS. Hippocampal melatonin receptors modulate seizure threshold. Epilepsia. (2005) 46:473-80. doi: 10.1111/j.0013-9580.2005.30204.x

90. Ray M, Mediratta PK, Reeta K, Mahajan P, Sharma KK. Receptor mechanisms involved in the anticonvulsant effect of melatonin in maximal electroshock seizures. Methods Find Exp Clin Pharmacol. (2004) 26:177-81. doi: 10.1358/mf.2004.26.3.809723

91. Fenoglio-Simeone K, Mazarati A, Sefidvash-Hockley S, Shin D, Wilke J, Milligan $\mathrm{H}$, et al. Anticonvulsant effects of the selective melatonin receptor agonist ramelteon. Epilepsy Behav. (2009) 16:52-7. doi: 10.1016/j.yebeh.2009.07.022
92. Tchekalarova J, Angelova VT, Todorova N, Andreeva-Gateva P, Rangelov M. Evaluation of the anticonvulsant effect of novel melatonin derivatives in the intravenous pentylenetetrazol seizure test in mice. Eur J Pharmacol. (2019) 863:172684. doi: 10.1016/j.ejphar.2019.172684

93. Angelova VT, Rangelov M, Todorova N, Dangalov M, Andreeva-Gateva P, Kondeva-Burdina $\mathrm{M}$, et al. Discovery of novel indole-based aroylhydrazones as anticonvulsants: pharmacophore-based design. Bioorg Chem. (2019) 90:103028. doi: 10.1016/j.bioorg.2019.103028

94. Yalyn O, Arman F, Erdogan F, Kula M. A comparison of the circadian rhythms and the levels of melatonin in patients with diurnal and nocturnal complex partial seizures. Epilepsy Behav. (2006) 8:542-6. doi: 10.1016/j.yebeh.2005.12.015

95. Bazil CW, Short D, Crispin D, Zheng W. Patients with intractable epilepsy have low melatonin, which increases following seizures. Neurology. (2000) 55:1746-8. doi: 10.1212/WNL.55.11.1746

96. Yahyavi-Firouz-Abadi N, Tahsili-Fahadan P, Riazi K, Ghahremani MH, Dehpour AR. Melatonin enhances the anticonvulsant and proconvulsant effects of morphine in mice: role for nitric oxide signaling pathway. Epilepsy Res. (2007) 75:138-44. doi: 10.1016/j.eplepsyres.2007.05.002

97. Sandyk R, Tsagas N, Anninos PA. Melatonin as a proconvulsive hormone in humans. Int J Neurosci. (1992) 63:125-35. doi: 10.3109/00207459208986662

98. Fauteck J, Schmidt H, Lerchl A, Kurlemann G, Wittkowski W. Melatonin in epilepsy: first results of replacement therapy and first clinical results. Biol Signals Recept. (1999) 8:105-10. doi: 10.1159/000014577

99. Stewart LS. Endogenous melatonin and epileptogenesis: facts and hypothesis. Int J Neurosci. (2001) 107:77-85. doi: 10.3109/00207450109149758

100. Mevissen M, Ebert U. Anticonvulsant effects of melatonin in amygdala-kindled rats. Neurosci Lett. (1998) 257:13-6. doi: 10.1016/S0304-3940(98)00790-3

101. Flourakis M, Kula-Eversole E, Hutchison AL, Han TH, Aranda K, Moose DL, et al. A conserved bicycle model for circadian clock control of membrane excitability. Cell. (2015) 162:836-48. doi: 10.1016/j.cell.2015.07.036

102. Whitt JP, Montgomery JR, Meredith AL. BK channel inactivation gates daytime excitability in the circadian clock. Nat Commun. (2016) 7:10837. doi: $10.1038 /$ ncomms 10837

103. Besing RC, Paul JR, Hablitz LM, Rogers CO, Johnson RL, Young ME, et al. Circadian rhythmicity of active GSK3 isoforms modulates molecular clock gene rhythms in the suprachiasmatic nucleus. J Biol Rhythms. (2015) 30:155-60. doi: 10.1177/0748730415573167

104. Paul JR, DeWoskin D, McMeekin LJ, Cowell RM, Forger DB, Gamble KL. Regulation of persistent sodium currents by glycogen synthase kinase 3 encodes daily rhythms of neuronal excitability. Nat Commun. (2016) 7:13470. doi: $10.1038 /$ ncomms 13470

105. Sahar S, Zocchi L, Kinoshita C, Borrelli E, Sassone-Corsi P. Regulation of BMAL1 protein stability and circadian function by GSK3beta-mediated phosphorylation. PLoS ONE. (2010) 5:e8561. doi: 10.1371/journal.pone.0008561

106. Iyer R, Wang TA, Gillette MU. Circadian gating of neuronal functionality: a basis for iterative metaplasticity. Front Syst Neurosci. (2014) 8:164. doi: $10.3389 /$ fnsys.2014.00164

107. Naseri Kouzehgarani G, Bothwell MY, Gillette MU. Circadian rhythm of redox state regulates membrane excitability in hippocampal CA1 neurons. Eur J Neurosci. (2019) 51:34-46. doi: 10.1111/ejn.14334

108. Jilg A, Lesny S, Peruzki N, Schwegler H, Selbach O, Dehghani F, et al. Temporal dynamics of mouse hippocampal clock gene expression support memory processing. Hippocampus. (2010) 20:377-88. doi: 10.1002/hipo.20637

109. Chun LE, Woodruff ER, Morton S, Hinds LR, Spencer RL. Variations in phase and amplitude of rhythmic clock gene expression across prefrontal cortex, hippocampus, amygdala, and hypothalamic paraventricular and suprachiasmatic nuclei of male and female rats. J Biol Rhythms. (2015) 30:417-36. doi: 10.1177/0748730415598608

110. Namihira M, Honma S, Abe H, Tanahashi Y, Ikeda M, Honma K. Daily variation and light responsiveness of mammalian clock gene, Clock and BMAL1, transcripts in the pineal body and different areas of brain in rats. Neurosci Lett. (1999) 267:69-72. doi: 10.1016/S0304-3940(99)00324-9

111. Honma S, Ikeda M, Abe H, Tanahashi Y, Namihira M, Honma K, et al. Circadian oscillation of BMAL1, a partner of a mammalian clock gene 
Clock, in rat suprachiasmatic nucleus. Biochem Biophys Res Commun. (1998) 250:83-7. doi: 10.1006/bbrc.1998.9275

112. Harbour VL, Weigl Y, Robinson B, Amir S. Phase differences in expression of circadian clock genes in the central nucleus of the amygdala, dentate gyrus, and suprachiasmatic nucleus in the rat. PLoS ONE. (2014) 9:e103309. doi: 10.1371/journal.pone.0103309

113. Wang LM, Dragich JM, Kudo T, Odom IH, Welsh DK, O'Dell TJ, et al. Expression of the circadian clock gene Period2 in the hippocampus: possible implications for synaptic plasticity and learned behaviour. ASN Neuro. (2009) 1:e00012. doi: 10.1042/AN20090020

114. Lamont EW, Robinson B, Stewart J, Amir S. The central and basolateral nuclei of the amygdala exhibit opposite diurnal rhythms of expression of the clock protein Period2. Proc Natl Acad Sci USA. (2005) 102:4180-4. doi: 10.1073/pnas.0500901102

115. Wakamatsu H, Yoshinobu Y, Aida R, Moriya T, Akiyama M, Shibata S. Restricted-feeding-induced anticipatory activity rhythm is associated with a phase-shift of the expression of mPer 1 and mPer2 mRNA in the cerebral cortex and hippocampus but not in the suprachiasmatic nucleus of mice. Eur J Neurosci. (2001) 13:1190-6. doi: 10.1046/j.0953-816x.2001.01483.x

116. Besing RC, Rogers CO, Paul JR, Hablitz LM, Johnson RL, McMahon LL, et al. GSK3 activity regulates rhythms in hippocampal clock gene expression and synaptic plasticity. Hippocampus. (2017) 27:890-8. doi: 10.1002/hipo.22739

117. Chaudhury D, Wang LM, Colwell CS. Circadian regulation of hippocampal long-term potentiation. J Biol Rhythms. (2005) 20:225-36. doi: $10.1177 / 0748730405276352$

118. Gerstner JR, Yin JC. Circadian rhythms and memory formation. Nat Rev Neurosci. (2010) 11:577-88. doi: 10.1038/nrn2881

119. Pena-de-Ortiz S, Jamieson GA Jr. Molecular cloning and brain localization of HZF-2 alpha, a new member of the Rev-erb subfamily of orphan nuclear receptors. J Neurobiol. (1997) 32:341-58.

120. Valnegri P, Khelfaoui M, Dorseuil O, Bassani S, Lagneaux C, Gianfelice A, et al. A circadian clock in hippocampus is regulated by interaction between oligophrenin-1 and Rev-erbalpha. Nat Neurosci. (2011) 14:1293301. doi: 10.1038/nn.2911

121. Gilhooley MJ, Pinnock SB, Herbert J. Rhythmic expression of per1 in the dentate gyrus is suppressed by corticosterone: implications for neurogenesis. Neurosci Lett. (2011) 489:177-81. doi: 10.1016/j.neulet.2010.12.011

122. Kole MH, Koolhaas JM, Luiten PG, Fuchs E. High-voltage-activated $\mathrm{Ca} 2+$ currents and the excitability of pyramidal neurons in the hippocampal CA3 subfield in rats depend on corticosterone and time of day. Neurosci Lett. (2001) 307:53-6. doi: 10.1016/S0304-3940(01) 01926-7

123. Galimberti CA, Magri F, Copello F, Arbasino C, Cravello L, Casu M, et al. Seizure frequency and cortisol and dehydroepiandrosterone sulfate (DHEAS) levels in women with epilepsy receiving antiepileptic drug treatment. Epilepsia. (2005) 46:517-23. doi: 10.1111/j.0013-9580.2005.59704.x

124. Fenoglio-Simeone KA, Wilke JC, Milligan HL, Allen CN, Rho JM, Maganti RK. Ketogenic diet treatment abolishes seizure periodicity and improves diurnal rhythmicity in epileptic Kcnal-null mice. Epilepsia. (2009) 50:202734. doi: 10.1111/j.1528-1167.2009.02163.x

125. Smart SL, Lopantsev V, Zhang CL, Robbins CA, Wang H, Chiu SY, et al. Deletion of the KV1.1 potassium channel causes epilepsy in mice. Neuron. (1998) 20:809-19. doi: 10.1016/S0896-6273(00)81018-1

126. Wright S, Wallace E, Hwang Y, Maganti R. Seizure phenotypes, periodicity, and sleep-wake pattern of seizures in Kcna-1 null mice. Epilepsy Behav. (2016) 55:24-9. doi: 10.1016/j.yebeh.2015.11.028

127. Patel DC, Tewari BP, Chaunsali L, Sontheimer H. Neuron-glia interactions in the pathophysiology of epilepsy. Nat Rev Neurosci. (2019) 20:282-97. doi: 10.1038/s41583-019-0126-4

128. Volterra A, Steinhauser C. Glial modulation of synaptic transmission in the hippocampus. Glia. (2004) 47:249-57. doi: 10.1002/glia.20080

129. Fellin T, Pascual O, Gobbo S, Pozzan T, Haydon PG, Carmignoto G. Neuronal synchrony mediated by astrocytic glutamate through activation of extrasynaptic NMDA receptors. Neuron. (2004) 43:729-43. doi: 10.1016/j.neuron.2004.08.011

130. Gomez-Gonzalo M, Losi G, Chiavegato A, Zonta M, Cammarota $\mathrm{M}$, Brondi $\mathrm{M}$, et al. An excitatory loop with astrocytes contributes to drive neurons to seizure threshold. PLoS Biol. (2010) 8:e1000352. doi: 10.1371/journal.pbio.1000352

131. Losi G, Cammarota M, Carmignoto G. The role of astroglia in the epileptic brain. Front Pharmacol. (2012) 3:132. doi: 10.3389/fphar.2012.00132

132. Binder DK. Astrocytes: stars of the sacred disease. Epilepsy Curr. (2018) 18:172-9. doi: 10.5698/1535-7597.18.3.172

133. Gerstner JR, Vanderheyden WM, LaVaute T, Westmark CJ, Rouhana L, Pack AI, et al. Time of day regulates subcellular trafficking, tripartite synaptic localization, and polyadenylation of the astrocytic Fabp7 mRNA. J Neurosci. (2012) 32:1383. doi: 10.1523/JNEUROSCI.3228-11.2012

134. Gerstner JR, Bremer QZ, Vander Heyden WM, Lavaute TM, Yin JC, Landry CF. Brain fatty acid binding protein (Fabp7) is diurnally regulated in astrocytes and hippocampal granule cell precursors in adult rodent brain. PLoS ONE. (2008) 3:e1631. doi: 10.1371/journal.pone.0001631

135. Owada $Y$, Yoshimoto $T$, Kondo H. Increased expression of the mRNA for brain- and skin-type but not heart-type fatty acid binding proteins following kainic acid systemic administration in the hippocampal glia of adult rats. Brain Res Mol Brain Res. (1996) 42:156-60. doi: 10.1016/S0169-328X(96)00182-9

136. Schnell A, Chappuis S, Schmutz I, Brai E, Ripperger JA, Schaad $\mathrm{O}$, et al. The nuclear receptor REV-ERB $\alpha$ regulates Fabp7 and modulates adult hippocampal neurogenesis. PLoS ONE. (2014) 9:e99883. doi: 10.1371/journal.pone.0099883

137. Gerstner JR, Paschos GK. Circadian expression of Fabp7 mRNA is disrupted in Bmall KO mice. Mol Brain. (2020) 13:26. doi: 10.1186/s13041-020-00568-7

138. Kim SH, Park HG, Jeong SH, Kang UG, Ahn YM, Kim YS. Electroconvulsive seizure alters the expression and daily oscillation of circadian genes in the rat frontal cortex. Psychiatry Investig. (2018) 15:717-26. doi: $10.30773 /$ pi.2018.01.18.2

139. Gerstner JR, Smith GG, Lenz O, Perron IJ, Buono RJ, Ferraro TN. BMAL1 controls the diurnal rhythm and set point for electrical seizure threshold in mice. Front Syst Neurosci. (2014) 8:121. doi: 10.3389/fnsys.2014.00121

140. Gerstner JR, Vanderheyden WM, Shaw PJ, Landry CF, Yin JC. Fatty-acid binding proteins modulate sleep and enhance long-term memory consolidation in Drosophila. PLoS ONE. (2011) 6:e15890. doi: 10.1371/journal.pone.0015890

141. Gerstner JR, Perron IJ, Riedy SM, Yoshikawa T, Kadotani H, Owada Y, et al. Normal sleep requires the astrocyte brain-type fatty acid binding protein FABP7. Sci Adv. (2017) 3:e1602663. doi: 10.1126/sciadv.1602663

142. Besing RC, Hablitz LM, Paul JR, Johnson RL, Prosser RA, Gamble KL. Neuropeptide Y-induced phase shifts of PER2::LUC rhythms are mediated by long-term suppression of neuronal excitability in a phase-specific manner. Chronobiol Int. (2012) 29:91-102. doi: 10.3109/07420528.2011.649382

143. Tringham E, Powell KL, Cain SM, Kuplast K, Mezeyova J, Weerapura $M$, et al. T-type calcium channel blockers that attenuate thalamic burst firing and suppress absence seizures. Sci Transl Med. (2012) 4:121ra119. doi: 10.1126/scitranslmed.3003120

144. Granados-Fuentes D, Hermanstyne TO, Carrasquillo Y, Nerbonne JM, Herzog ED. IA channels encoded by Kv1.4 and Kv4.2 regulate circadian period of PER2 expression in the suprachiasmatic nucleus. J Biol Rhythms. (2015) 30:396-407. doi: 10.1177/0748730415593377

145. Singh B, Ogiwara I, Kaneda M, Tokonami N, Mazaki E, Baba K, et al. A Kv4.2 truncation mutation in a patient with temporal lobe epilepsy. Neurobiol Dis. (2006) 24:245-53. doi: 10.1016/j.nbd.2006.07.001

146. Talathi SS, Hwang DU, Ditto WL, Mareci T, Sepulveda H, Spano M, et al. Circadian control of neural excitability in an animal model of temporal lobe epilepsy. Neurosci Lett. (2009) 455:145-9. doi: 10.1016/j.neulet.2009.03.057

147. Tahsili-Fahadan P, Yahyavi-Firouz-Abadi N, Riazi K, Ghahremani MH, Dehpour AR. Effect of acute and chronic photoperiod modulation on pentylenetetrazole-induced clonic seizure threshold in mice. Epilepsy Res. (2008) 82:64-9. doi: 10.1016/j.eplepsyres.2008.07.006

148. Matos HC, Koike BDV, Pereira WDS, de Andrade TG, Castro OW, Duzzioni $\mathrm{M}$, et al. Rhythms of core clock genes and spontaneous locomotor activity in post-status epilepticus model of mesial temporal lobe epilepsy. Front Neurol. (2018) 9:632. doi: 10.3389/fneur.2018.00632

149. Lipton JO, Boyle LM, Yuan ED, Hochstrasser KJ, Chifamba FF, Nathan A, et al. Aberrant proteostasis of BMAL1 underlies circadian 
abnormalities in a paradigmatic mTOR-opathy. Cell Rep. (2017) 20:868-80. doi: 10.1016/j.celrep.2017.07.008

150. Lipton JO, Yuan ED, Boyle LM, Ebrahimi-Fakhari D, Kwiatkowski E, Nathan A, et al. The circadian protein BMAL1 regulates translation in response to S6K1-mediated phosphorylation. Cell. (2015) 161:1138-51. doi: 10.1016/j.cell.2015.04.002

151. Gruber V, Scholl T, Samueli S, Gröppel G, Mühlebner A, Hainfellner JA, et al. Pathophysiology of neurodevelopmental mTOR pathway-associated epileptic conditions: current status of biomedical research. Clin Neuropathol. (2019) 38:210-24. doi: 10.5414/NP301214

152. Allen CN. Circadian rhythms, diet, and neuronal excitability. Epilepsia. (2008) 49(Suppl. 8):124-6. doi: 10.1111/j.1528-1167.2008.01856.x

153. Marcheva B, Ramsey KM, Buhr ED, Kobayashi Y, Su H, Ko CH, et al. Disruption of the clock components CLOCK and BMAL1 leads to hypoinsulinaemia and diabetes. Nature. (2010) 466:627-31. doi: 10.1038/nature09253

154. Hatanaka F, Matsubara C, Myung J, Yoritaka T, Kamimura N, Tsutsumi S, et al. Genome-wide profiling of the core clock protein BMAL1 targets reveals a strict relationship with metabolism. Mol Cell Biol. (2010) 30:5636-48. doi: 10.1128/MCB.00781-10

155. Klugmann M, Leichtlein CB, Symes CW, Klaussner BC, Brooks AI, Young D, et al. A novel role of circadian transcription factor DBP in hippocampal plasticity. Mol Cell Neurosci. (2006) 31:303-14. doi: 10.1016/j.mcn.2005.09.019

156. Martin AM, Sun EW, Keating DJ. Mechanisms controlling hormone secretion in human gut and its relevance to metabolism. J Endocrinol. (2019) 244:R1-15. doi: 10.1530/JOE-19-0399

157. Dienel GA, Carlson GM. Major advances in brain glycogen research: understanding of the roles of glycogen have evolved from emergency fuel reserve to dynamic, regulated participant in diverse brain functions. $A d v$ Neurobiol. (2019) 23:1-16. doi: 10.1007/978-3-030-27480-1_1

158. Li P, Fu X, Smith NA, Ziobro J, Curiel J, Tenga MJ, et al. Loss of CLOCK results in dysfunction of brain circuits underlying focal epilepsy. Neuron. (2017) 96:387-401.e386. doi: 10.1016/j.neuron.2017. 09.044

159. Santos EA, Marques TE, Matos Hde C, Leite JP, Garcia-Cairasco N, Paco-Larson ML, et al. Diurnal variation has effect on differential gene expression analysis in the hippocampus of the pilocarpine-induced model of mesial temporal lobe epilepsy. PLoS ONE. (2015) 10:e0141121. doi: 10.1371/journal.pone.0141121

160. Eun B, Kim HJ, Kim SY, Kim TW, Hong ST, Choi KM, et al. Induction of Per1 expression following an experimentally induced epilepsy in the mouse hippocampus. Neurosci Lett. (2011) 498:110-3. doi: 10.1016/j.neulet.2011.03.039

161. Park JS, Cederroth CR, Basinou V, Meltser I, Lundkvist G, Canlon B. Identification of a circadian clock in the inferior colliculus and its dysregulation by noise exposure. J Neurosci. (2016) 36:5509-19. doi: 10.1523/JNEUROSCI.3616-15.2016

162. Yi PL, Chen YJ, Lin CT, Chang FC. Occurrence of epilepsy at different zeitgeber times alters sleep homeostasis differently in rats. Sleep. (2012) 35:1651-65. doi: 10.5665/sleep.2238

163. Wiebking N, Maronde E, Rami A. Increased neuronal injury in clock gene Per-1 deficient-mice after cerebral ischemia. Curr Neurovasc Res. (2013) 10:112-25. doi: 10.2174/1567202611310020004

164. Guissart C, Latypova X, Rollier P, Khan TN, Stamberger H, McWalter K, et al. Dual molecular effects of dominant RORA mutations cause two variants of syndromic intellectual disability with either autism or cerebellar ataxia. Am J Hum Genet. (2018) 102:744-59. doi: 10.1016/j.ajhg.2018.02.021

165. Epi25 Collaborative. Ultra-rare genetic variation in the epilepsies: a wholeexome sequencing study of 17,606 individuals. Am J Hum Genet. (2019) 105:267-82. doi: 10.1016/j.ajhg.2019.05.020

166. International League Against Epilepsy Consortium on Complex Epilepsies. Genome-wide mega-analysis identifies 16 loci and highlights diverse biological mechanisms in the common epilepsies. Nat Commun. (2018) 9:5269. doi: 10.1038/s41467-018-07524-z

167. Hamilton BA, Frankel WN, Kerrebrock AW, Hawkins TL, FitzHugh W, Kusumi K, et al. Disruption of the nuclear hormone receptor RORalpha in staggerer mice. Nature. (1996) 379:736-9. doi: 10.1038/379736a0
168. Cohen BH, Chinnery PF, Copeland WC. POLG-related disorders. In: GeneReviews $^{T M}$. (2018). Available online at: http://www.ncbi.nlm.nih.gov/ books/NBK26471/

169. Sax DS, Hirano A, Shofer RJ. Staggerer, a neurological murine mutant. An electron microscopic study of the cerebellar cortex in the adult. Neurology. (1968) 18:1093-100. doi: 10.1212/WNL.18.11.1093

170. Online Mendelian Inheritance in Man, OMIM. Johns Hopkins University, Baltimore, MD. MIM Number: $\{606220\}$. Available online at: https://omim. org/entry/606220 (accessed April 11, 2019).

171. Online Mendelian Inheritance in Man, OMIM. Johns Hopkins University, Baltimore, MD. MIM Number: \{256731\}. Available online at: https://omim.org/entry/256731\#molecularGenetics (accessed March 11, 2016).

172. Online Mendelian Inheritance in Man, OMIM. Johns Hopkins University, Baltimore, MD. MIM Number: $\{604348\}$. Available online at: https://omim. org/entry/604348 (accessed May 25, 2005).

173. Online Mendelian Inheritance in Man, OMIM. Johns Hopkins University, Baltimore, MD. MIM Number: $\{614163\}$. Available online at: https://www. omim.org/entry/614163 (accessed May 22, 2017).

174. Santos B, Marques T, Malta M, Gameleira F, Secolin R, Andrade T, et al. PER2 rs2304672, CLOCK rs1801260, and PER3 rs57875989 polymorphisms are not associated with juvenile myoclonic epilepsy. Epilepsy Behav. (2014) 36:82-5. doi: 10.1016/j.yebeh.2014.04.024

175. Lossin C, Rhodes TH, Desai RR, Vanoye CG, Wang D, Carniciu $\mathrm{S}$, et al. Epilepsy-associated dysfunction in the voltage-gated neuronal sodium channel SCN1A. J Neurosci. (2003) 23:11289-95. doi: 10.1523/JNEUROSCI.23-36-11289.2003

176. Han S, Yu FH, Schwartz MD, Linton JD, Bosma MM, Hurley JB, et al. $\mathrm{Na}(\mathrm{V}) 1.1$ channels are critical for intercellular communication in the suprachiasmatic nucleus and for normal circadian rhythms. Proc Natl Acad Sci USA. (2012) 109:E368-77. doi: 10.1073/pnas.1115729109

177. Kalume F, Oakley JC, Westenbroek RE, Gile J, de la Iglesia HO, Scheuer $\mathrm{T}$, et al. Sleep impairment and reduced interneuron excitability in a mouse model of Dravet Syndrome. Neurobiol Dis. (2015) 77:141-54. doi: 10.1016/j.nbd.2015.02.016

178. Smolensky MH, Lemmer B, Reinberg AE. Chronobiology and chronotherapy of allergic rhinitis and bronchial asthma. Adv Drug Deliv Rev. (2007) 59:852-82. doi: 10.1016/j.addr.2007.08.016

179. Tekade AR, Gattani SG. Dual cross-linked pulsatile beads for chronotherapy of asthma: development and evaluation. Drug Deliv. (2010) 17:581-6. doi: 10.3109/10717544.2010.501460

180. Acelajado MC, Pisoni R, Dudenbostel T, Oparil S, Calhoun DA, Glasser SP. Both morning and evening dosing of nebivolol reduces trough mean blood pressure surge in hypertensive patients. J Am Soc Hypertens. (2012) 6:66-72. doi: 10.1016/j.jash.2011.09.001

181. Manganaro S, Loddenkemper T, Rotenberg A. The need for antiepileptic drug chronotherapy to treat selected childhood epilepsy syndromes and avert the harmful consequences of drug resistance. J Cent Nerv Syst Dis. (2017) 9:1179573516685883. doi: 10.1177/1179573516685883

182. Shih K-C, Hsieh S-H, Kwok C-F, Hwu C-M, Hsieh P-S, Ho L-T. Effect of growth hormone on dawn phenomenon in patients with type 2 diabetes. Growth Fact. (2013) 31:66-73. doi: 10.3109/08977194.2013.772996

183. Amengual-Gual M, Sánchez Fernández I, Loddenkemper T. Patterns of epileptic seizure occurrence. Brain Res. (2019) 1703:3-12. doi: 10.1016/j.brainres.2018.02.032

184. Khedhaier WBC, Dridi I, Aouam K, Ben-Attia M, Reinberg A, Boughattas NA. Circadian variation in anticonvulsant activity of valproic acid in mice. Biomed Pharmacother. (2017) 95:25-30. doi: 10.1016/j.biopha.2017.08.047

185. Yegnanarayan R, Mahesh SD, Sangle S. Chronotherapeutic dose schedule of phenytoin and carbamazepine in epileptic patients. Chronobiol Int. (2006) 23:1035-46. doi: 10.1080/07420520600921112

186. Guilhoto LMFF, Loddenkemper T, Vendrame M, Bergin A, Bourgeois BF, Kothare SV. Higher evening antiepileptic drug dose for nocturnal and early-morning seizures. Epilepsy Behav. (2011) 20:334-7. doi: $10.1016 /$ j.yebeh.2010.11.017

187. Thome-Souza S, Klehm J, Jackson M, Kadish NE, Manganaro S, Fernández IS, et al. Clobazam higher-evening differential dosing as an add-on therapy in refractory epilepsy. Seizure. (2016) 40:1-6. doi: 10.1016/j.seizure.2016.05.014 
188. Hofstra WA, van der Palen J, de Weerd AW. Morningness and eveningness: when do patients take their antiepileptic drugs? Epilepsy Behav. (2012) 23:320-3. doi: 10.1016/j.yebeh.2011. 12.008

189. Kendis H, Baron K, Schuele SU, Patel B, Attarian H. Chronotypes in patients with epilepsy: does the type of epilepsy make a difference? Behav Neurol. (2015) 2015:4. doi: 10.1155/2015/941354

190. Paul JR, Davis JA, Goode LK, Becker BK, Fusilier A, Meador-Woodruff A, et al. Circadian regulation of membrane physiology in neural oscillators throughout the brain. Eur J Neurosci. (2020) 51:109-38. doi: $10.1111 /$ ejn. 14343
Conflict of Interest: The authors declare that the research was conducted in the absence of any commercial or financial relationships that could be construed as a potential conflict of interest.

Copyright (๑) 2020 Re, Batterman, Gerstner, Buono and Ferraro. This is an openaccess article distributed under the terms of the Creative Commons Attribution License (CC BY). The use, distribution or reproduction in other forums is permitted, provided the original author(s) and the copyright owner(s) are credited and that the original publication in this journal is cited, in accordance with accepted academic practice. No use, distribution or reproduction is permitted which does not comply with these terms. 